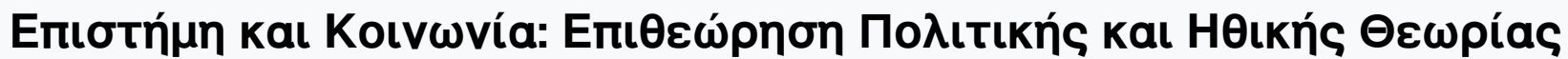

Tóp. 28 (2011)

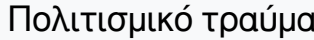
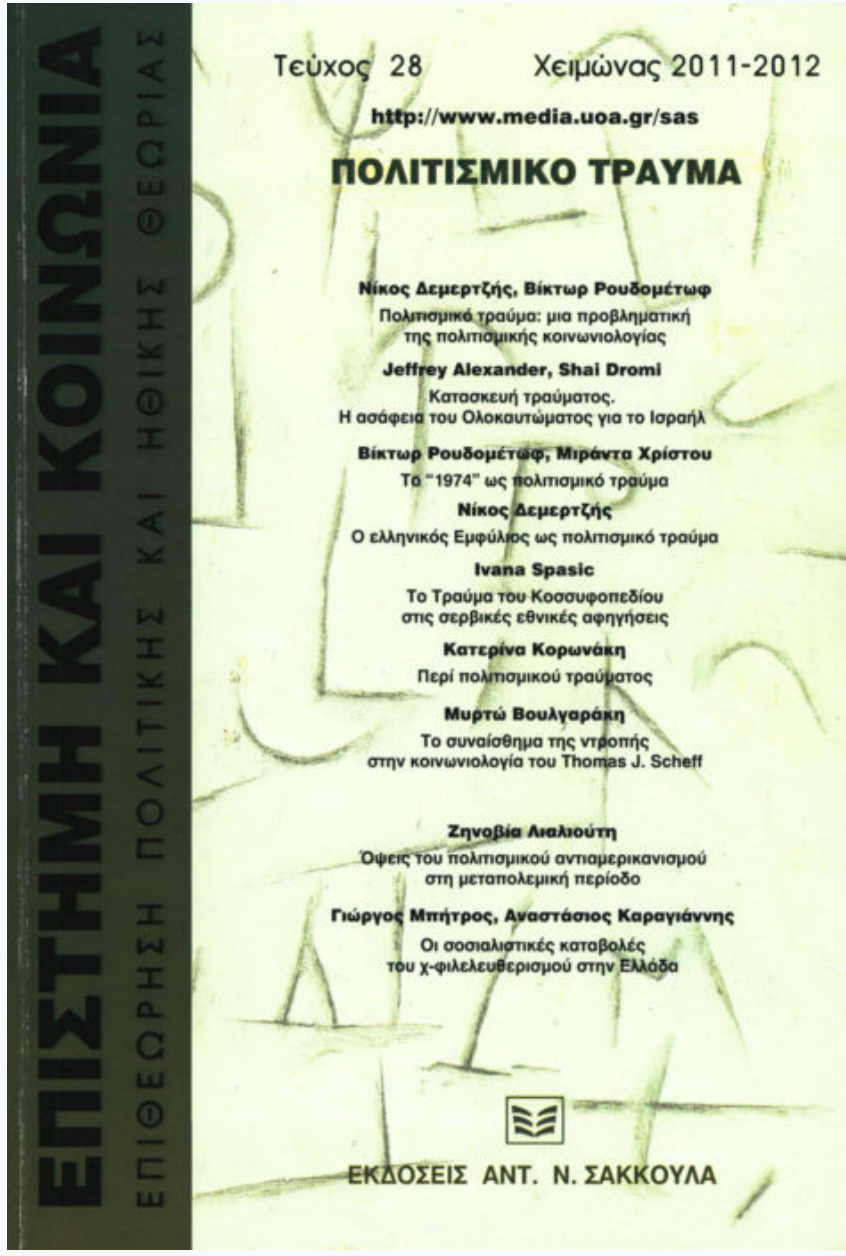

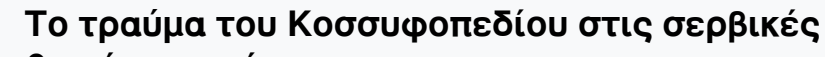

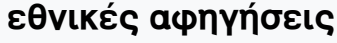

Ivana Spasić

doi: $10.12681 /$ sas.822

Copyright @ 2015

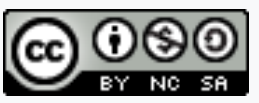

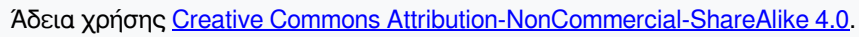

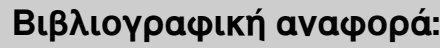

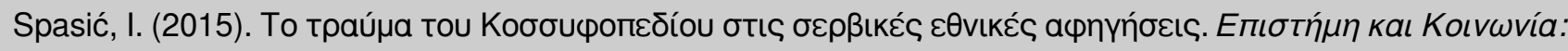

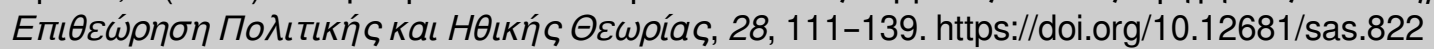




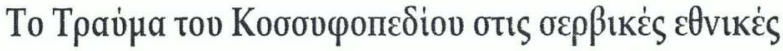

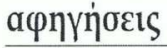

Ivana Spasić*

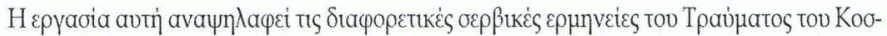

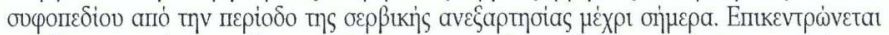

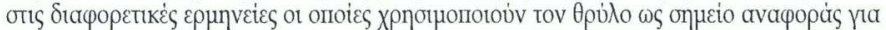

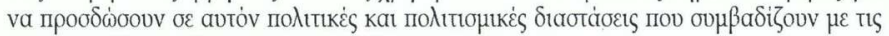

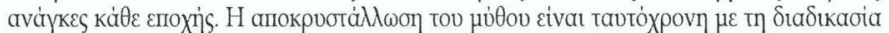

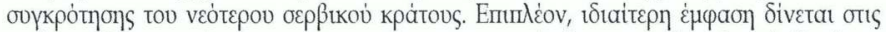

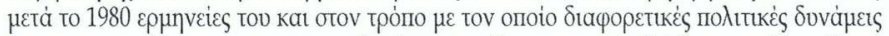

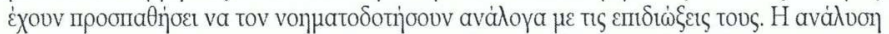

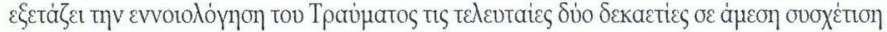

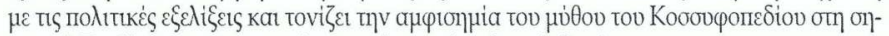

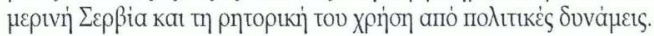

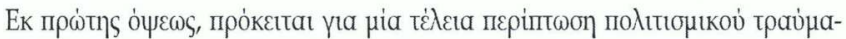

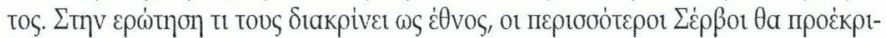

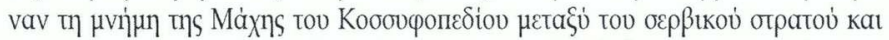

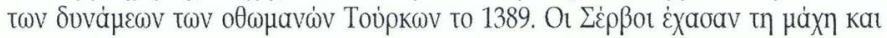

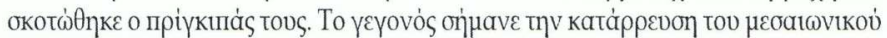

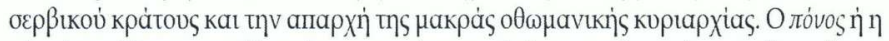

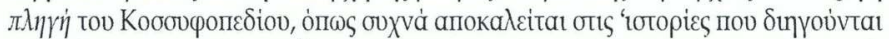

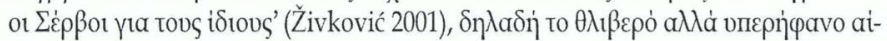

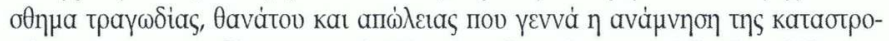

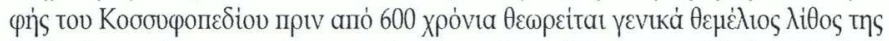

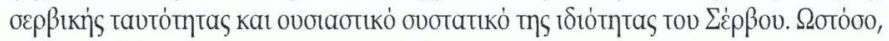

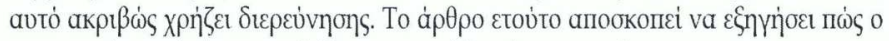

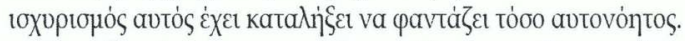

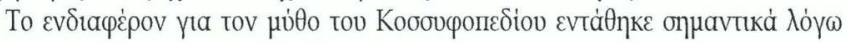

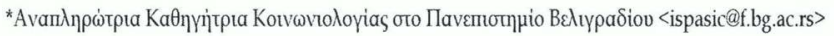




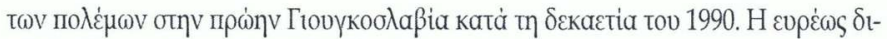

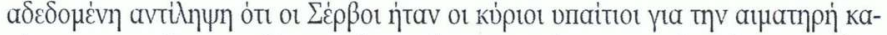

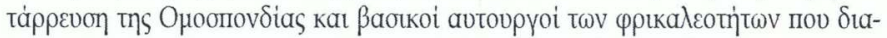

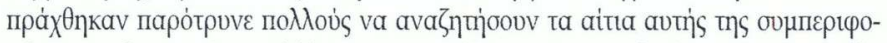

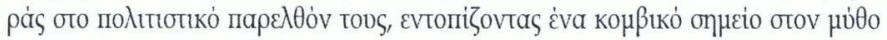

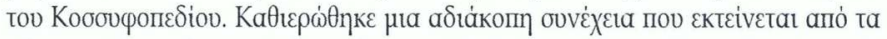

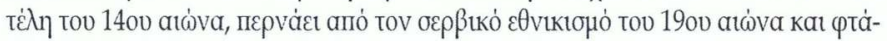

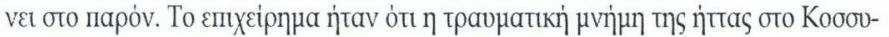

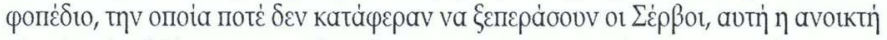

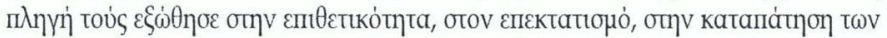

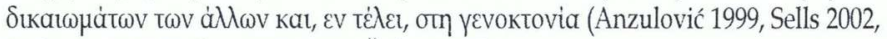
Vetlesen 2005, Volkan 1996, 2002, Šuber 2006).

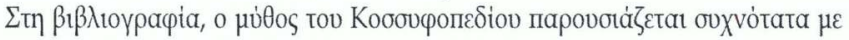

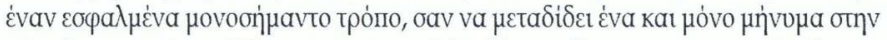

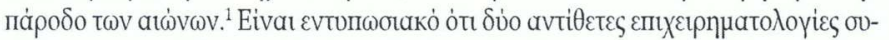

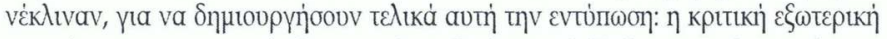

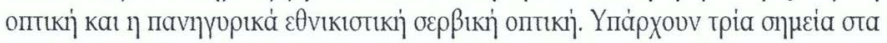

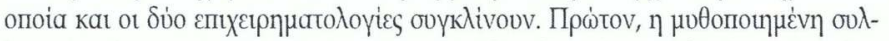

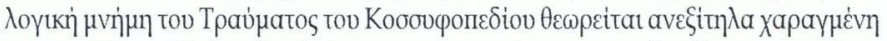

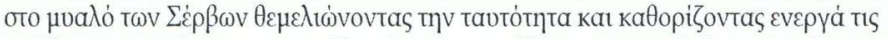

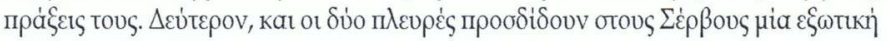

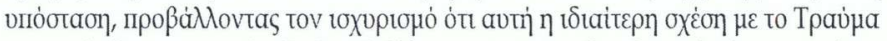

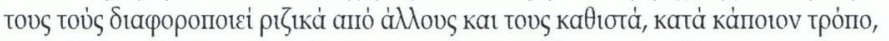

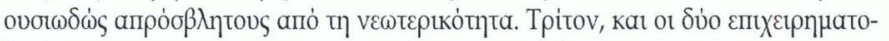

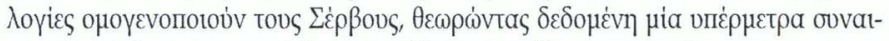

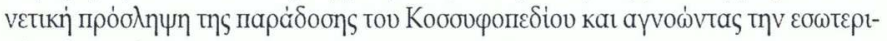

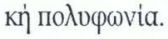

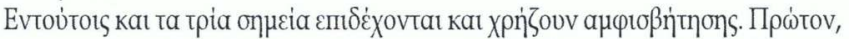

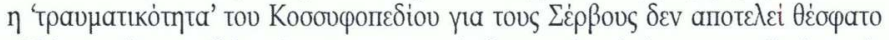

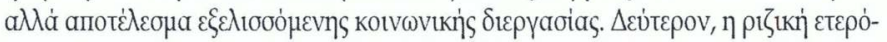

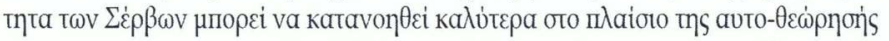

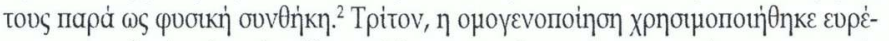

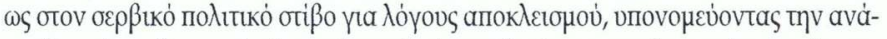

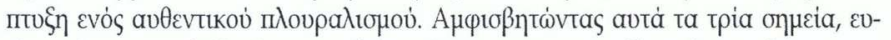

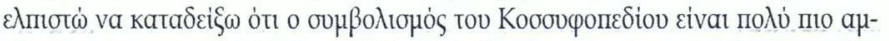

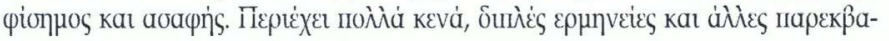




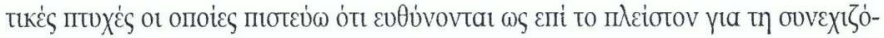

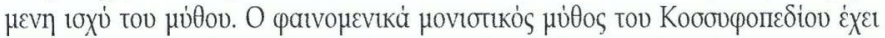

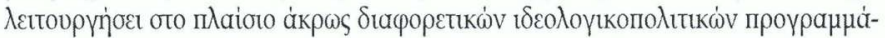

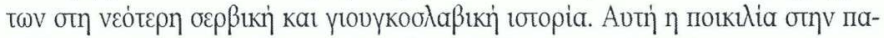

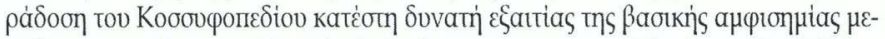

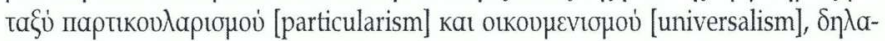
$\delta \dot{\eta} \mu t a \varsigma$ a a

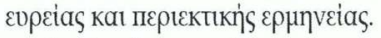

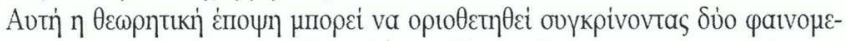

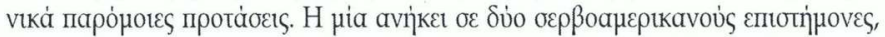

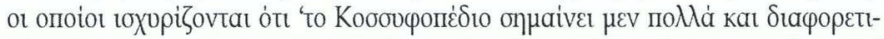

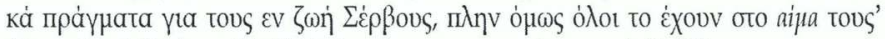

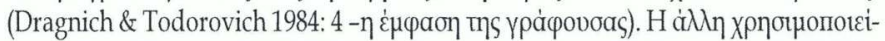

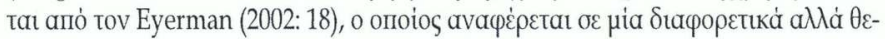

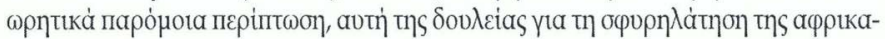

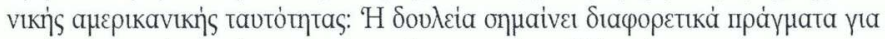

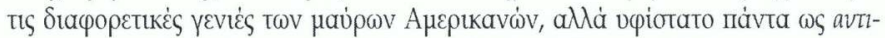

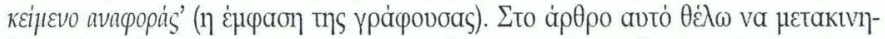

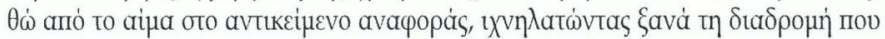

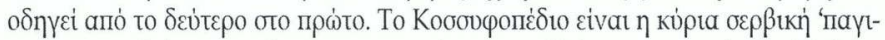

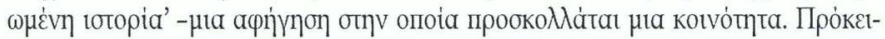
та丿 үra a

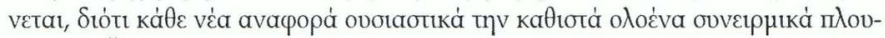

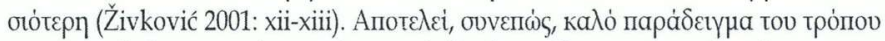

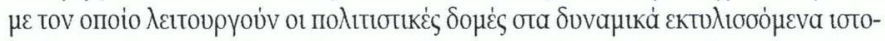

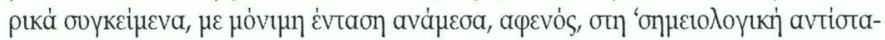
оп' т

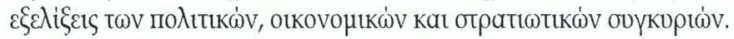

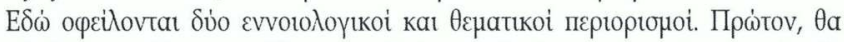

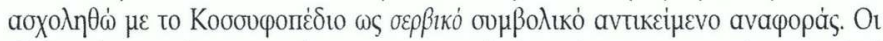

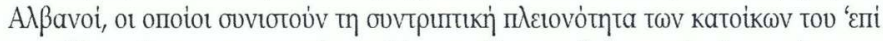

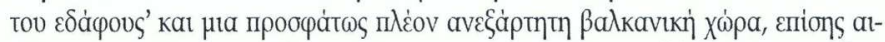

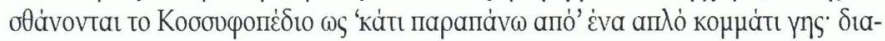

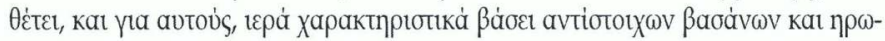

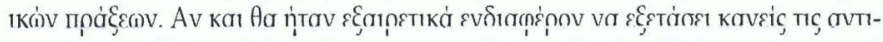

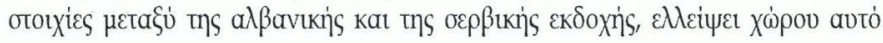




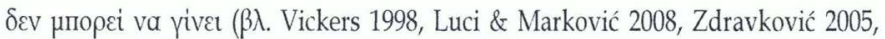

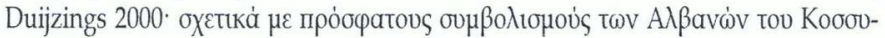

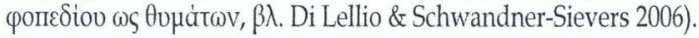

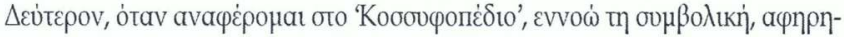

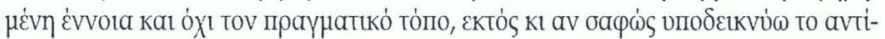

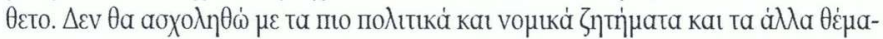

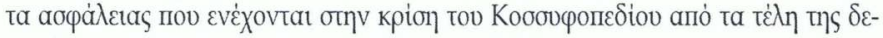

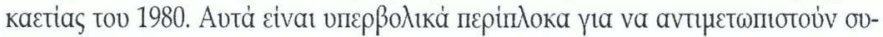

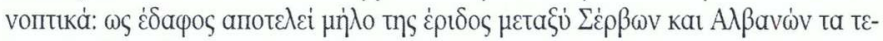

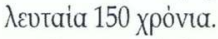

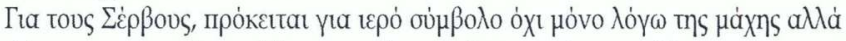

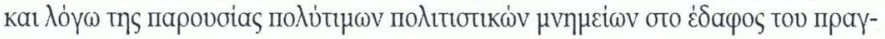

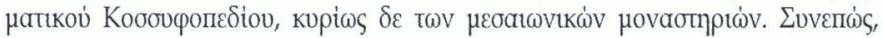

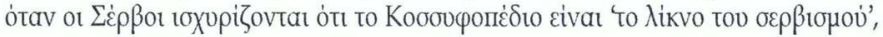

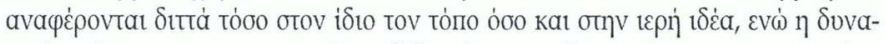

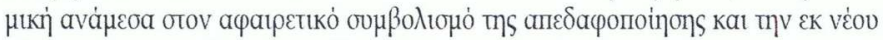

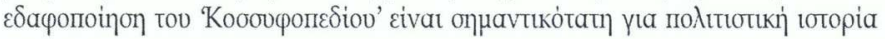
T̄ৎ Ėvvotas.

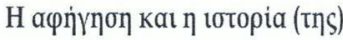

\section{Н аларху}

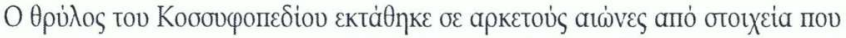

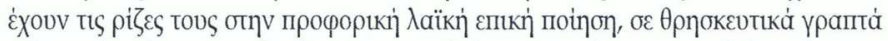

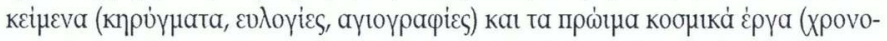

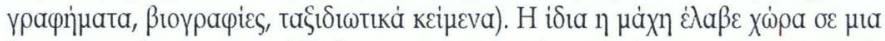

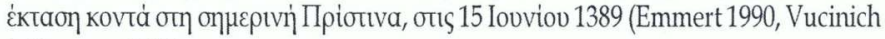
\& Emmert 1991).

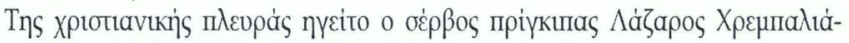

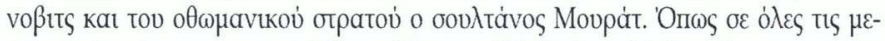

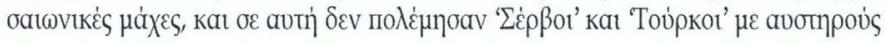

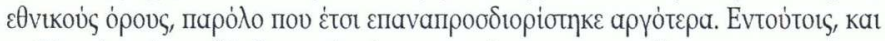

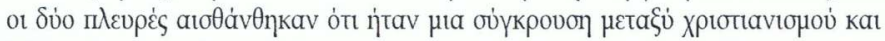

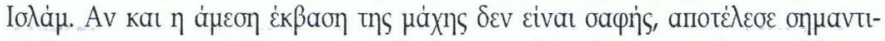

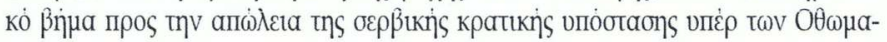




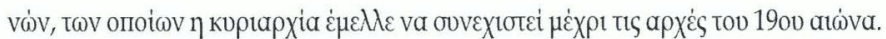

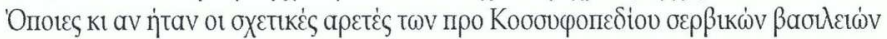

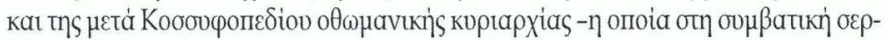

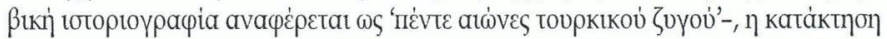

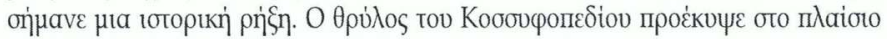

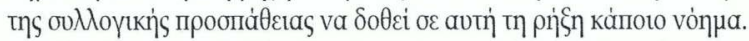

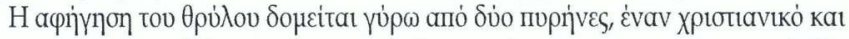

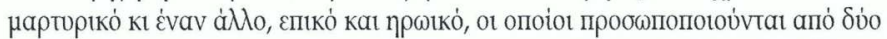

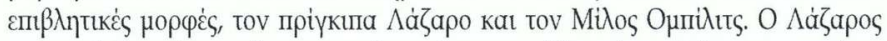

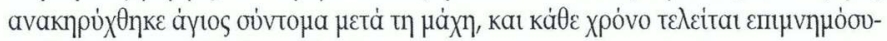

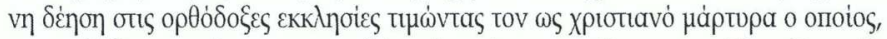

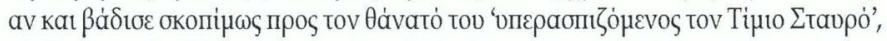

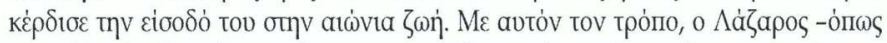

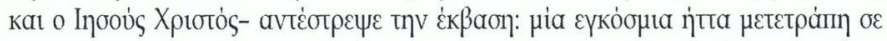

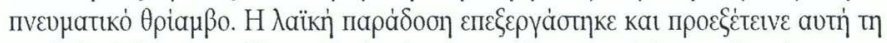

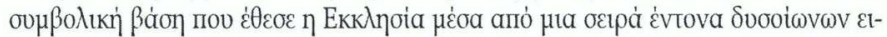

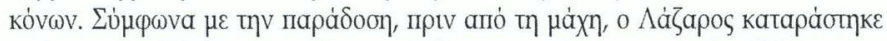

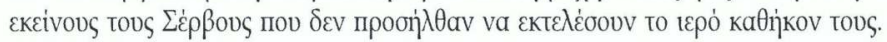

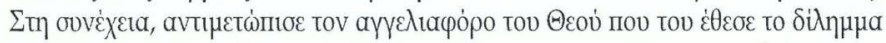

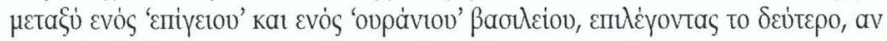

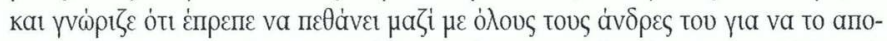

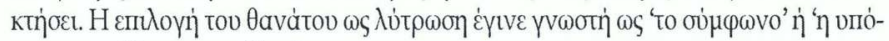

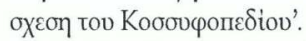

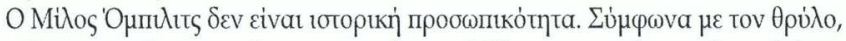

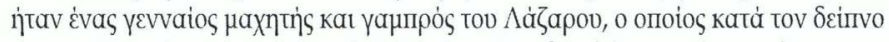

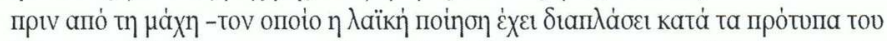

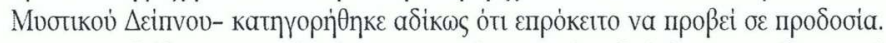

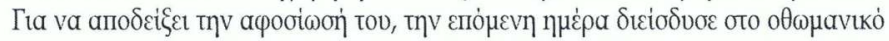

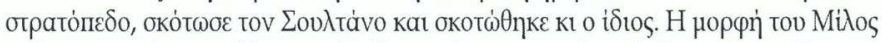

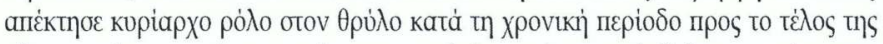

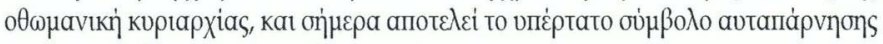

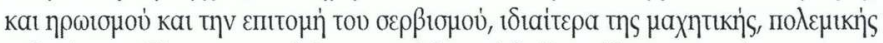

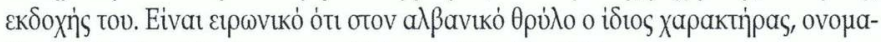

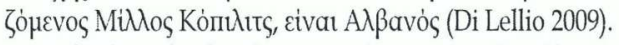

O Aṇì

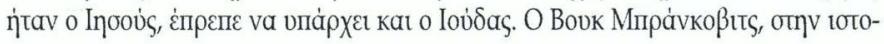




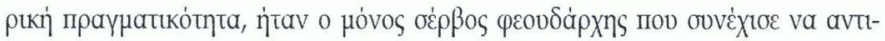

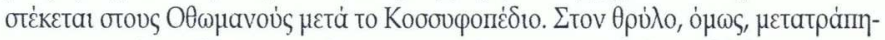

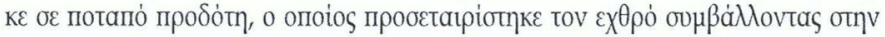

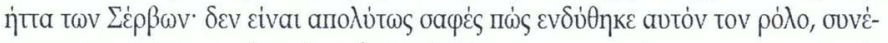

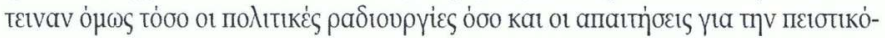

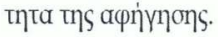

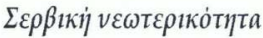

$\Delta \varepsilon v$ vпंрх тіпот

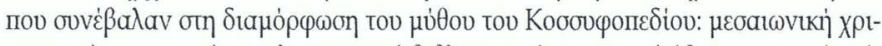

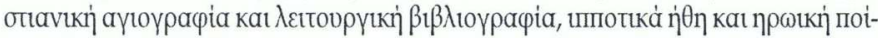

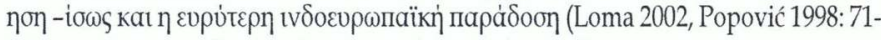

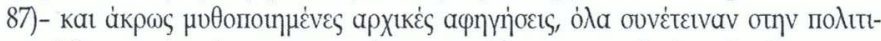

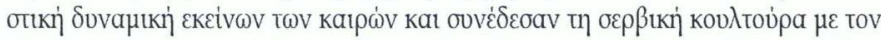

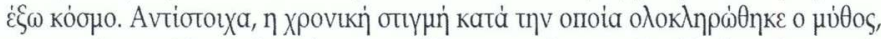

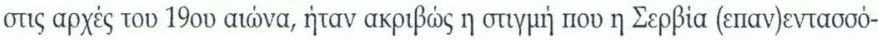

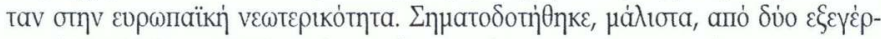

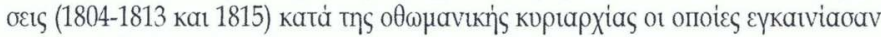

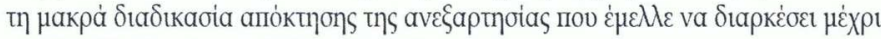
to 1878 ( $\beta \lambda$. Roudometof 2001: 101-129).

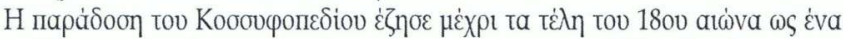

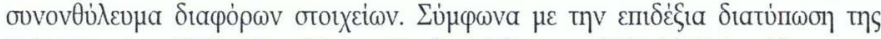

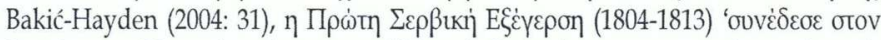

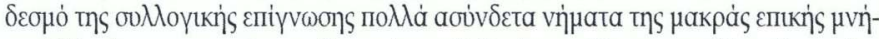

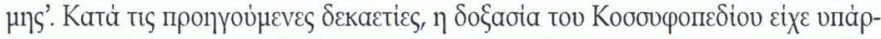

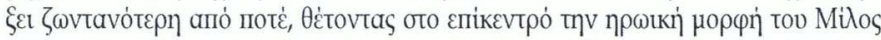

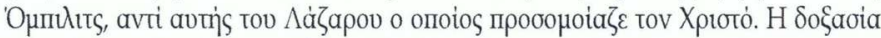

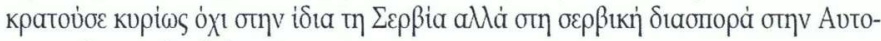

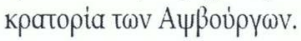

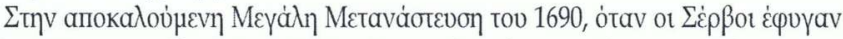

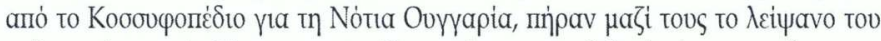

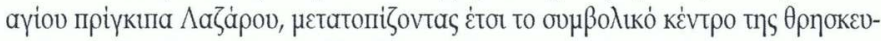

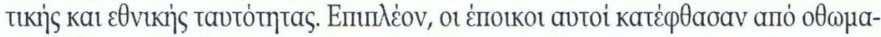

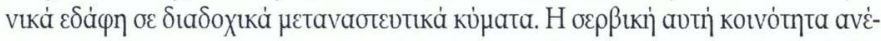

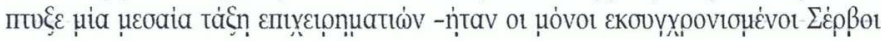




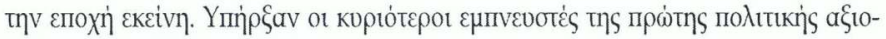

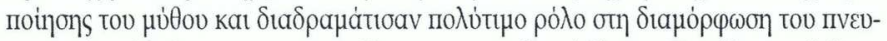

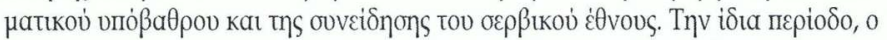

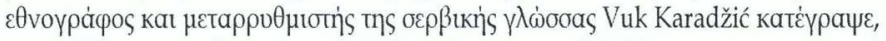

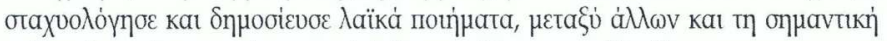

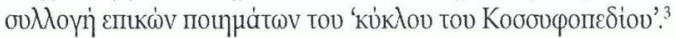

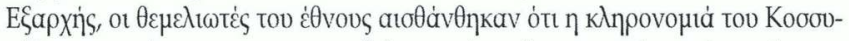

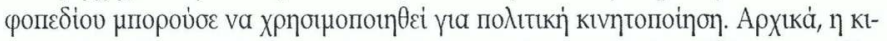

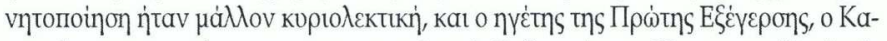

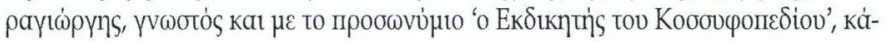

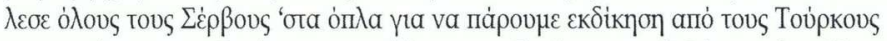

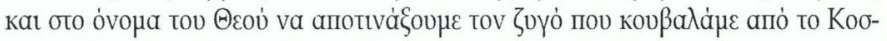

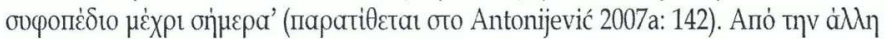

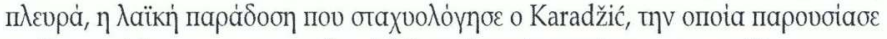

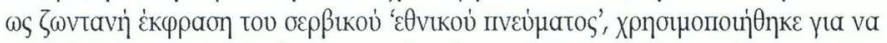

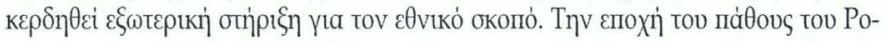

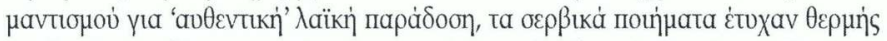

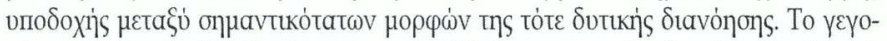

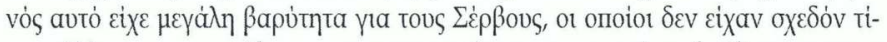

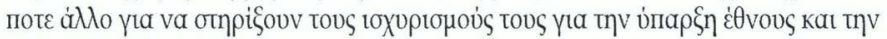

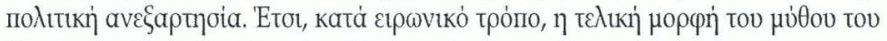
Кобоu

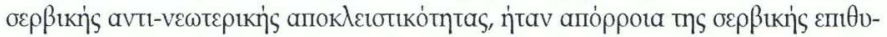

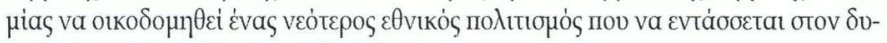

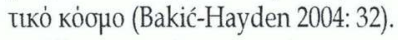

Гиं

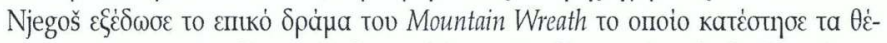

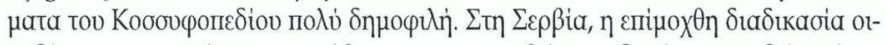

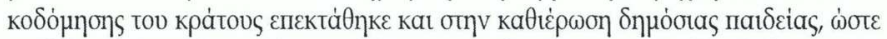

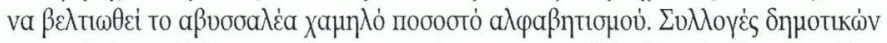

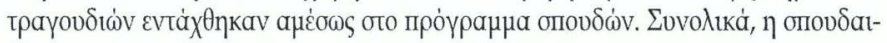

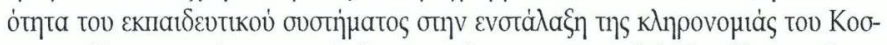

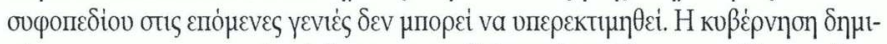

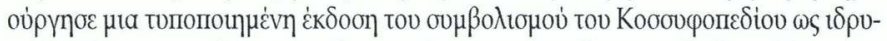

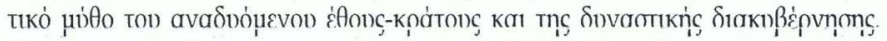

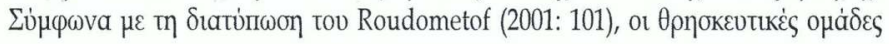




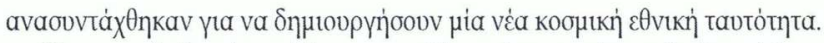

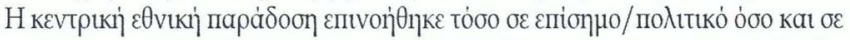

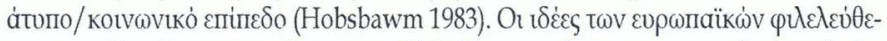

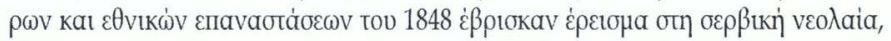

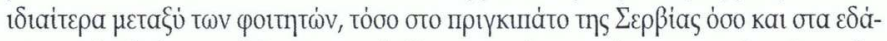

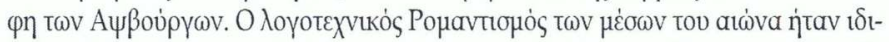

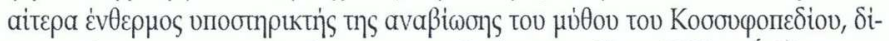

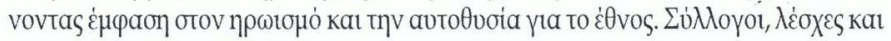

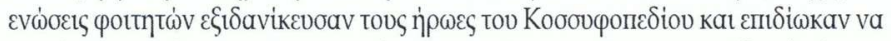

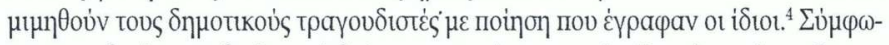

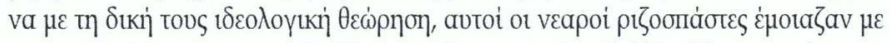

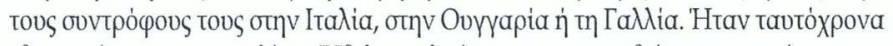

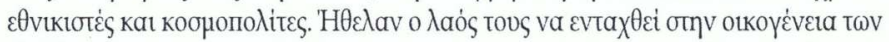

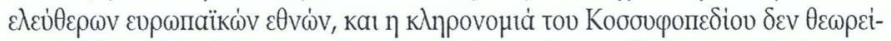

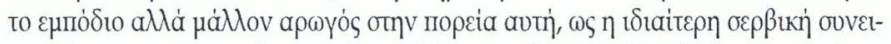

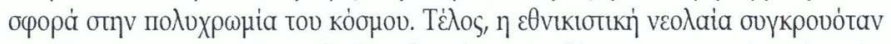

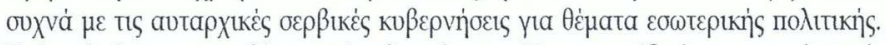

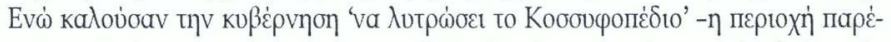

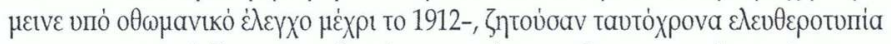

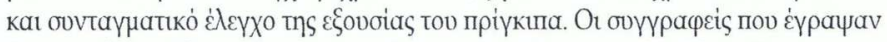

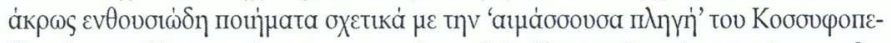

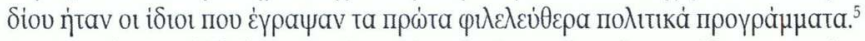

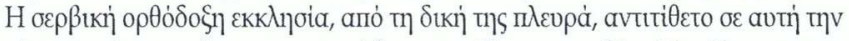

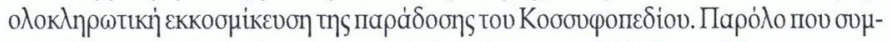

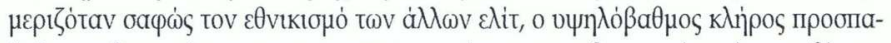

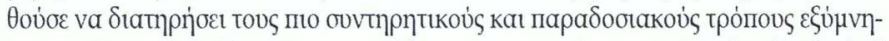

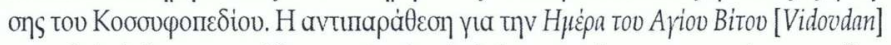

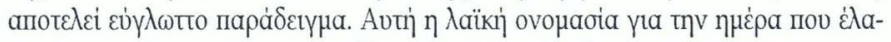

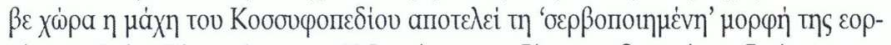

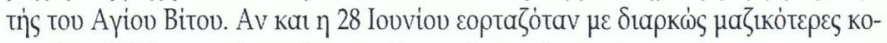

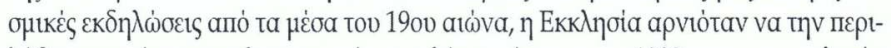

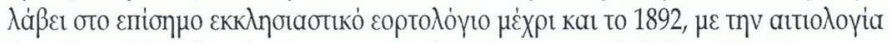

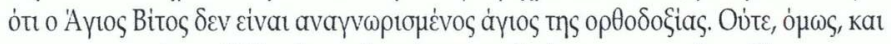

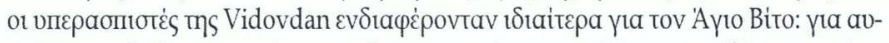

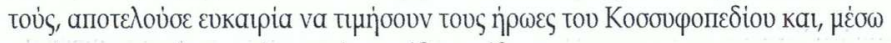

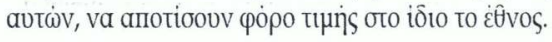




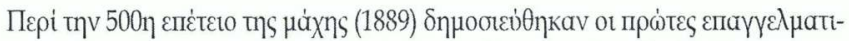

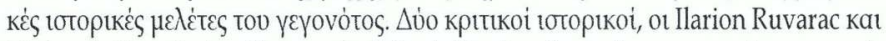

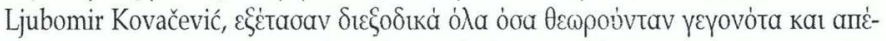

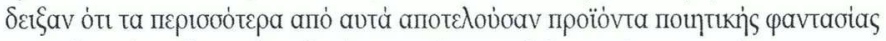

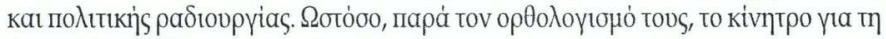

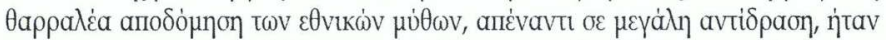

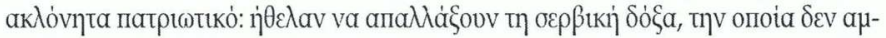

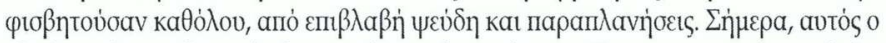

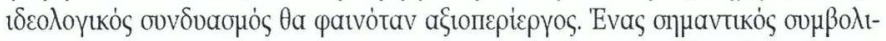

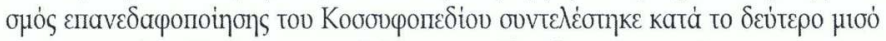

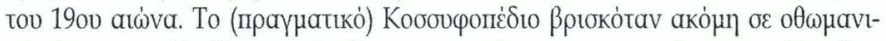

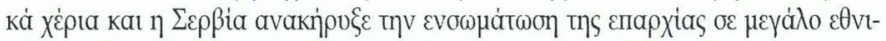

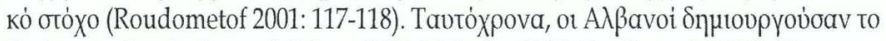

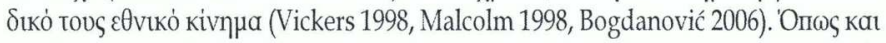

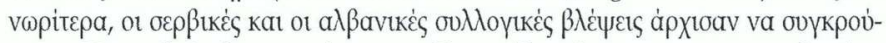

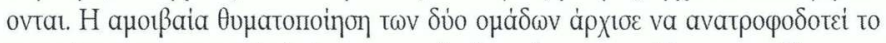
ортота่

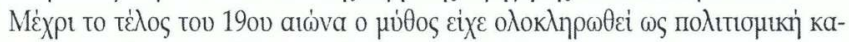

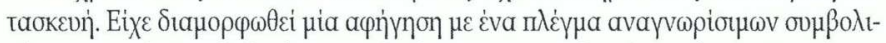

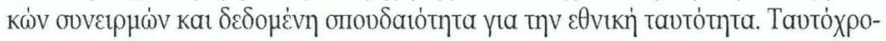

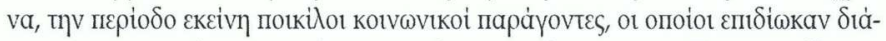

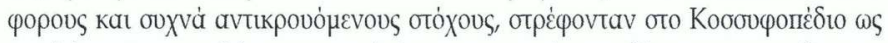

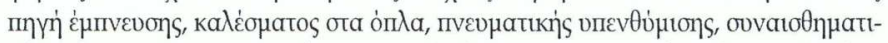

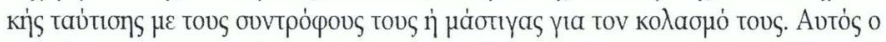

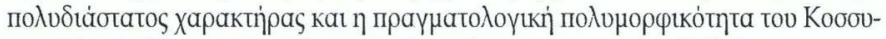

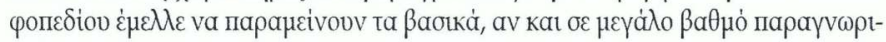

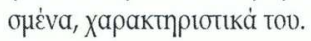

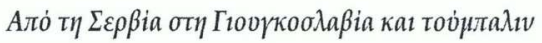

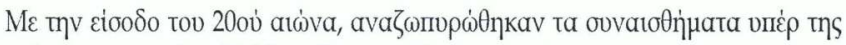

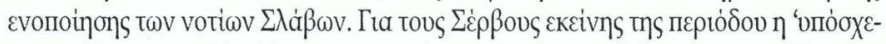

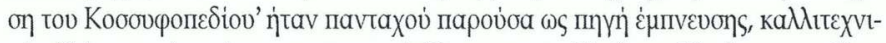

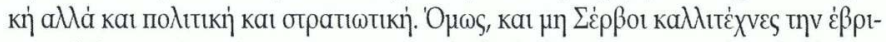

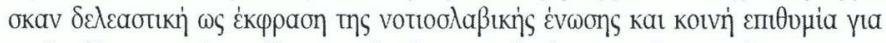

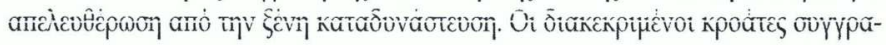




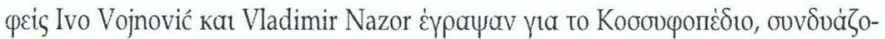

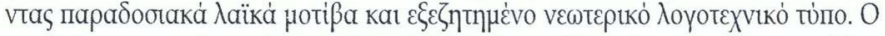

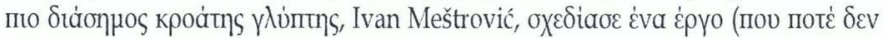

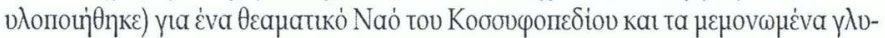

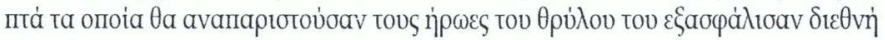
$\varphi \eta \dot{\mu \eta} .^{6}$

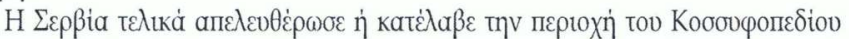

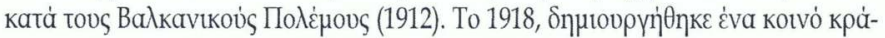

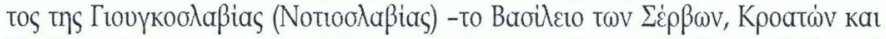

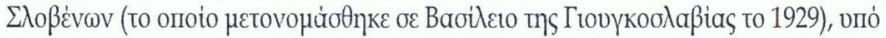

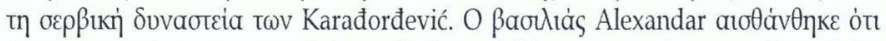

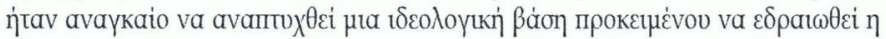

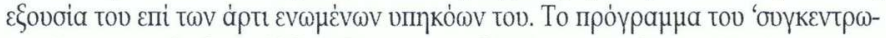

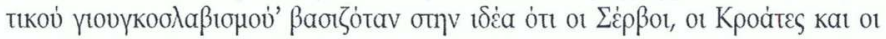

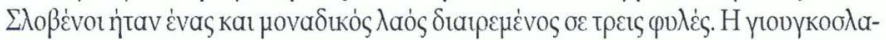

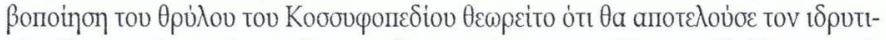

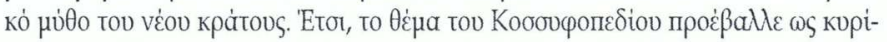

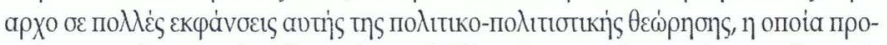

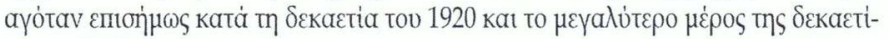
as tov 1930.

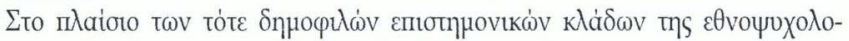

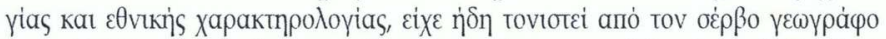

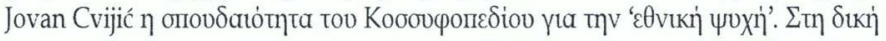

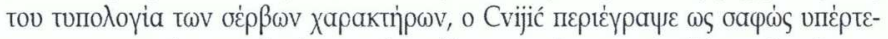

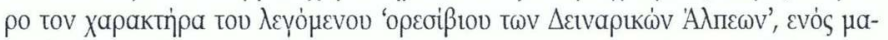

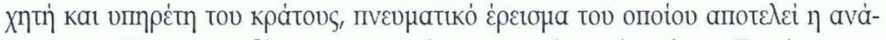

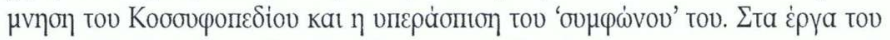

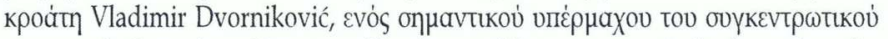

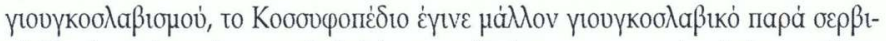

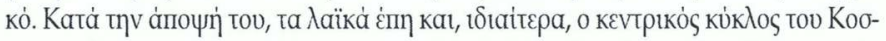

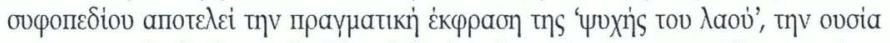

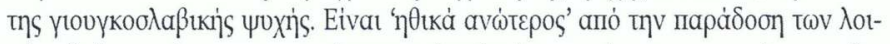

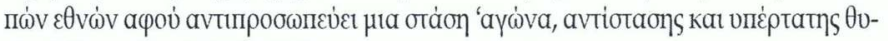
oias' (Dvorniković 1939: 537).

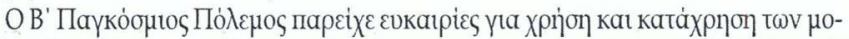

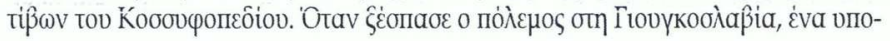




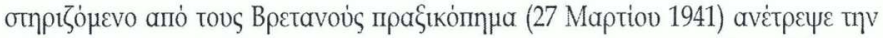

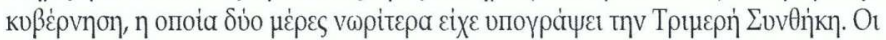

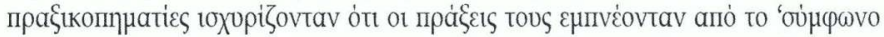

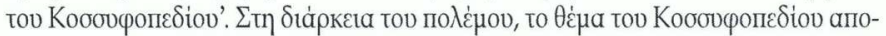

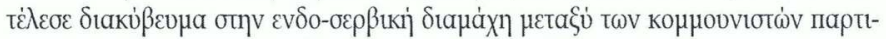

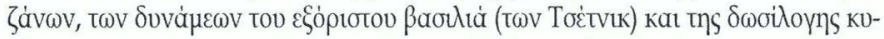

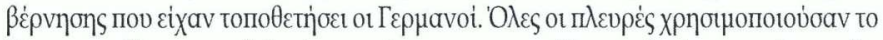

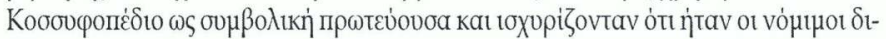

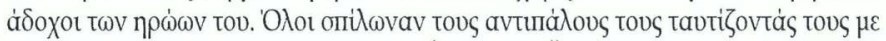
tov Bovk Mпрávкoßtтs (Emmert 1990, Ćosić 2004, Žanić 1998).

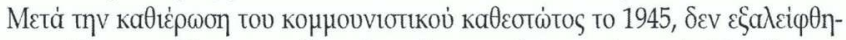

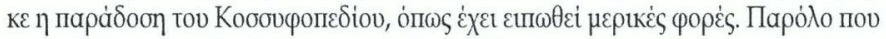

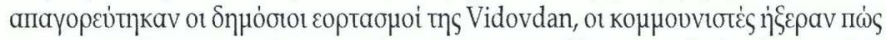

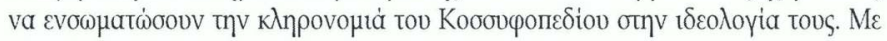

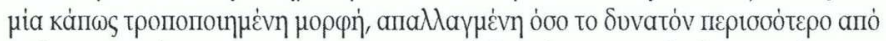

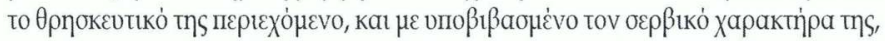

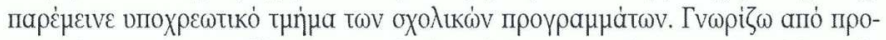

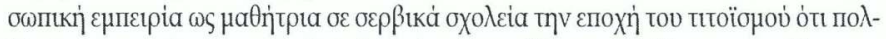
$\lambda \dot{s} \varsigma \dot{\omega} \rho \varepsilon \varsigma$ a

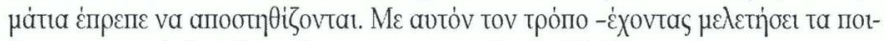

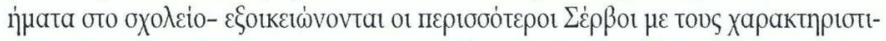

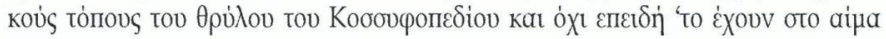
Tous'.

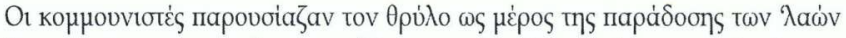

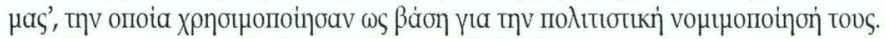

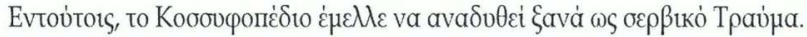

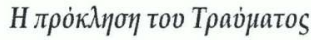

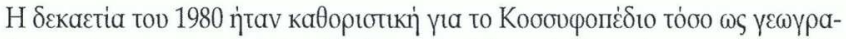

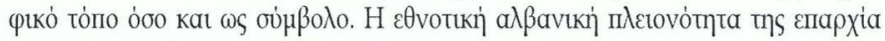

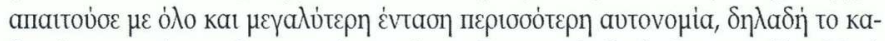
$\theta \varepsilon \sigma \omega \dot{s} \mu$ tas

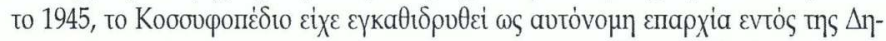

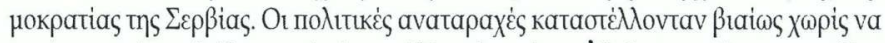

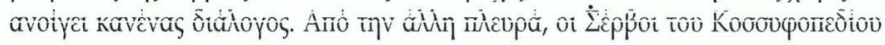




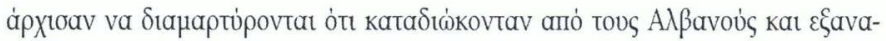

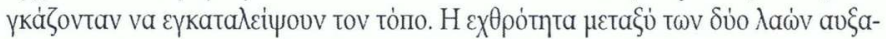

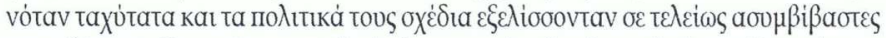

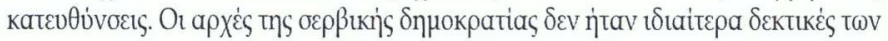

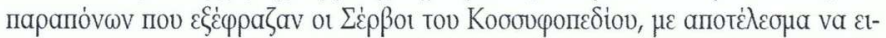

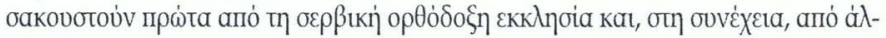

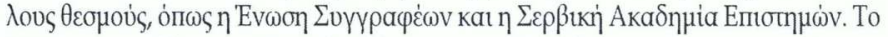

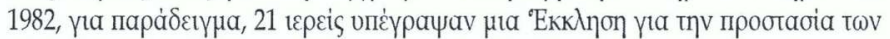

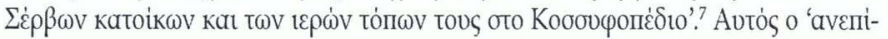

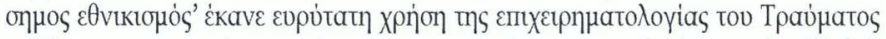

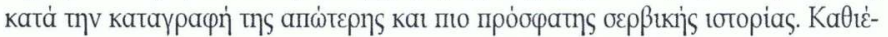

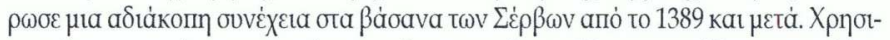

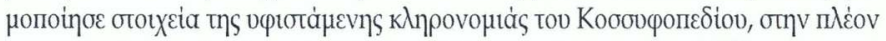

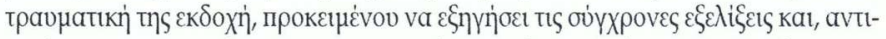
бро́

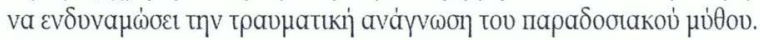

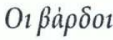

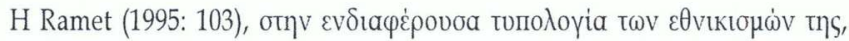

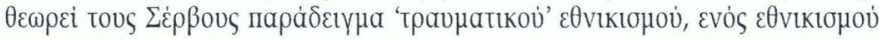

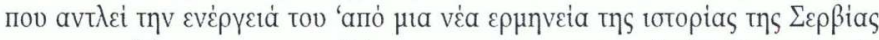

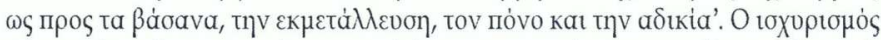

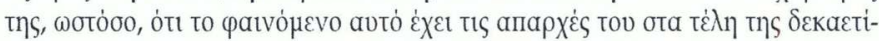

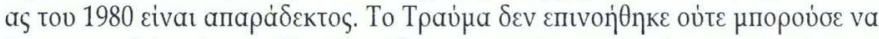

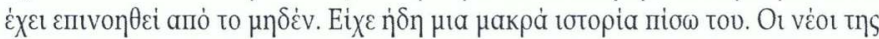

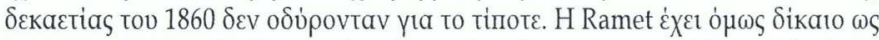

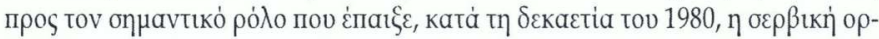

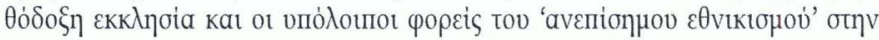

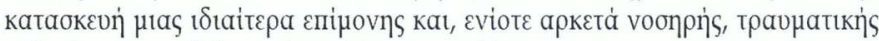

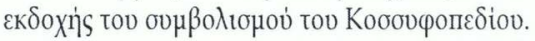

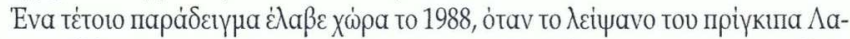

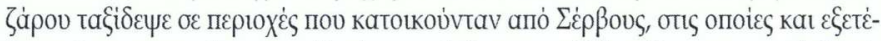

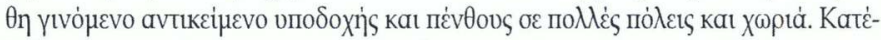

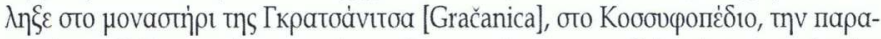

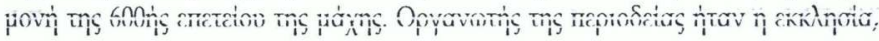




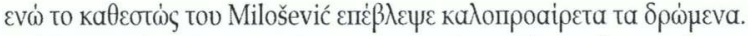

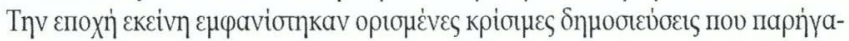

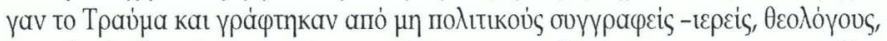

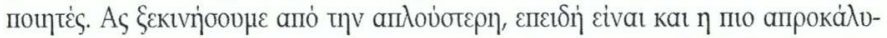

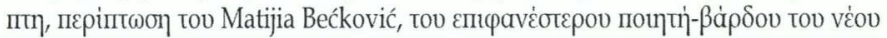

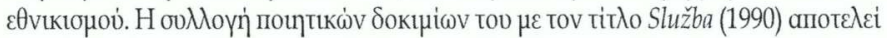

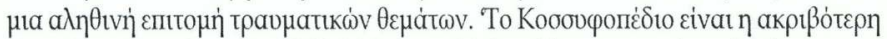

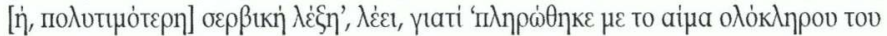

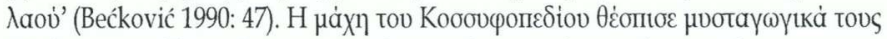

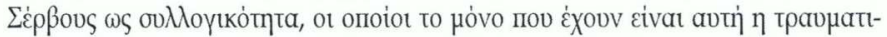

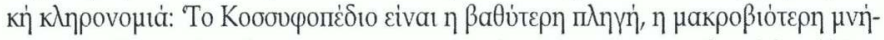

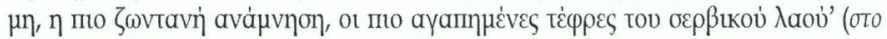

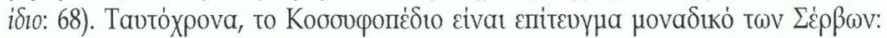

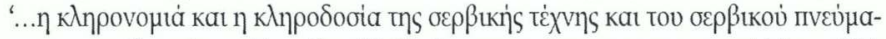

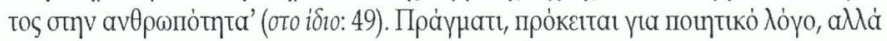

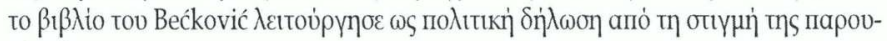
oiaons tov.

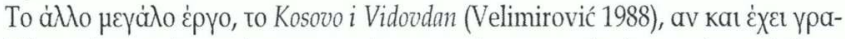

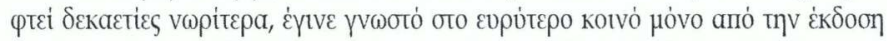

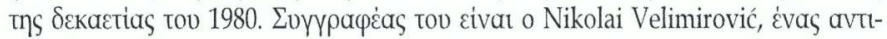

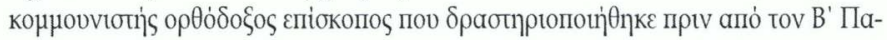

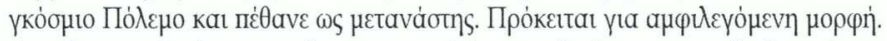

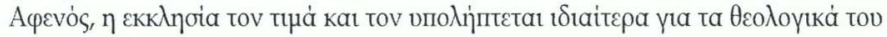

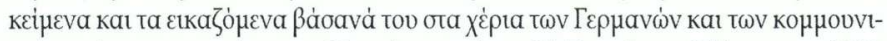

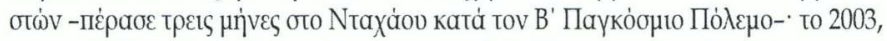

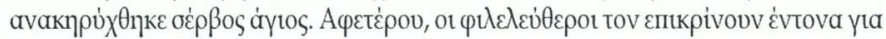

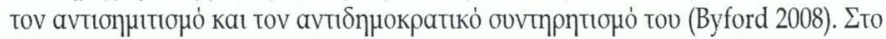

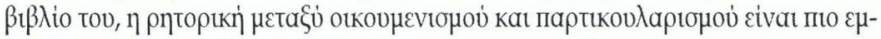

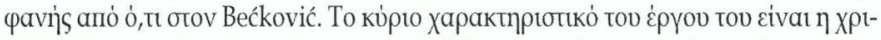

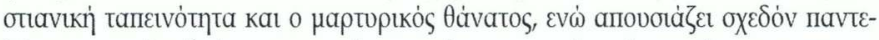

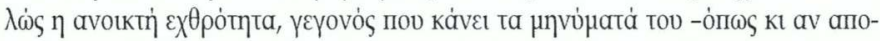

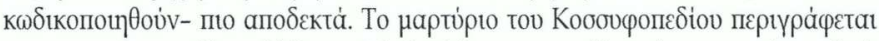

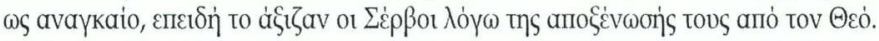

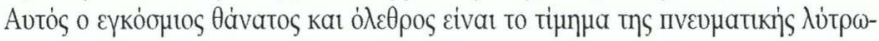

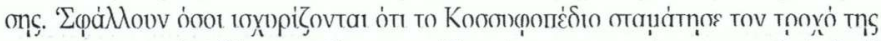

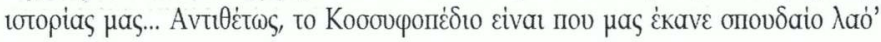




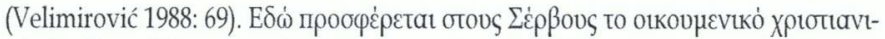

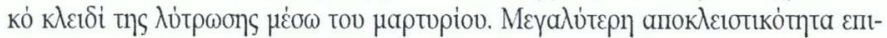

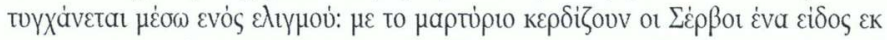
т

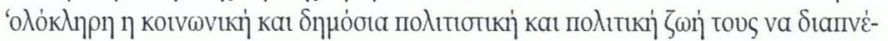

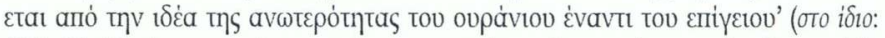

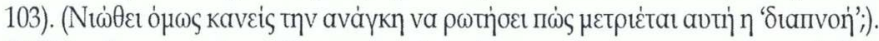

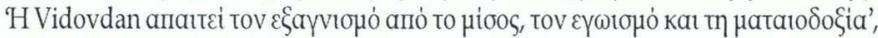

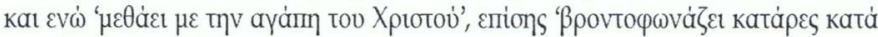

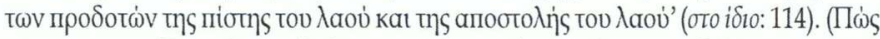

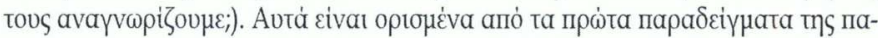

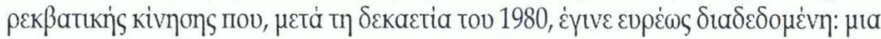

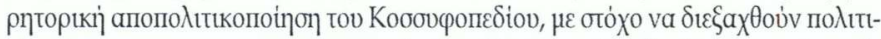

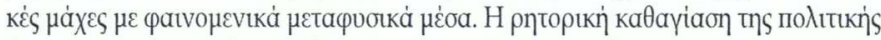

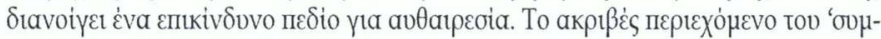

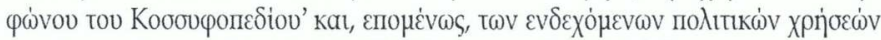

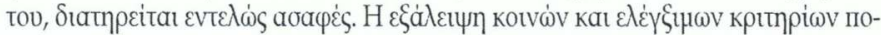

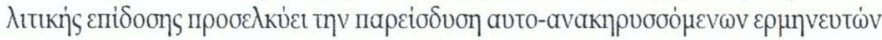

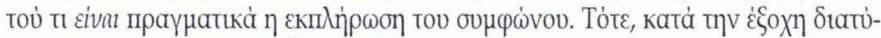

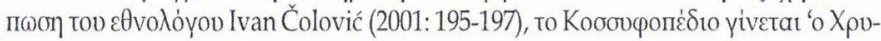

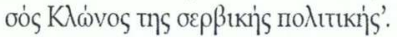

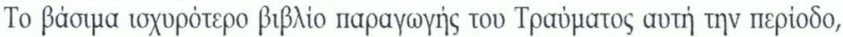

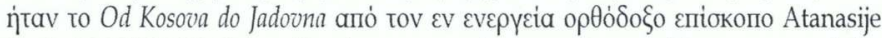

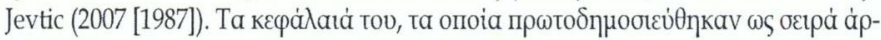

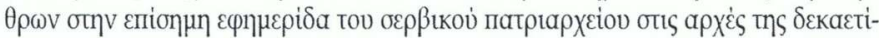

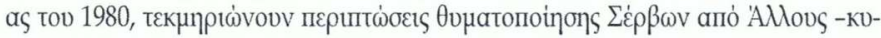

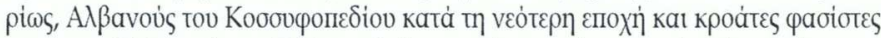

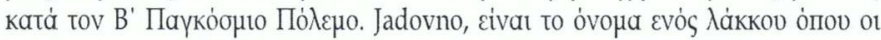

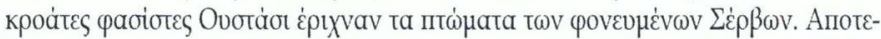

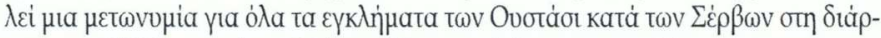

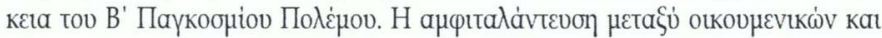

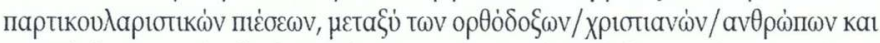

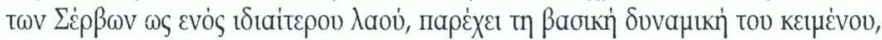

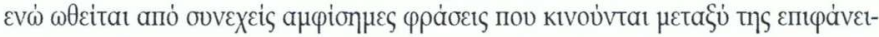

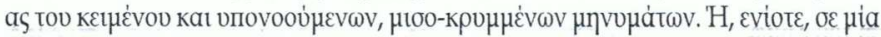

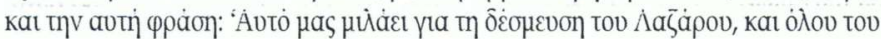




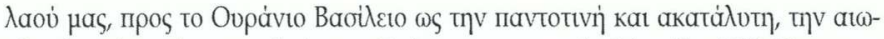

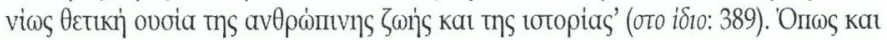

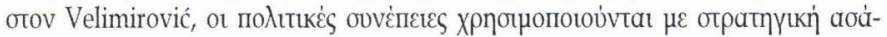

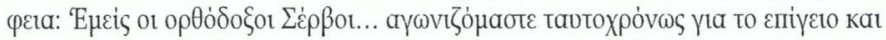

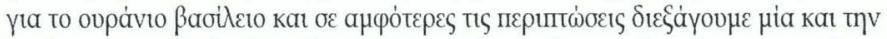

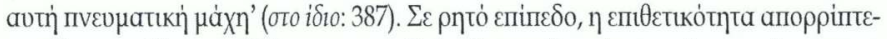

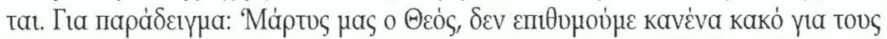

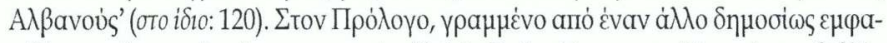

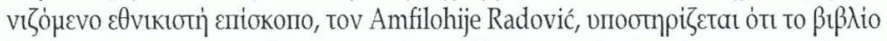

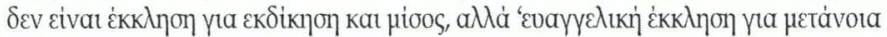

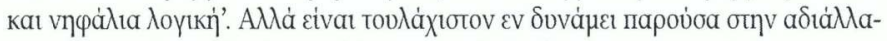

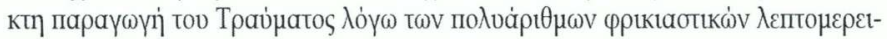

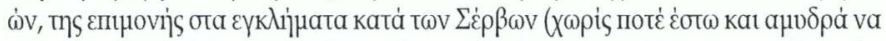

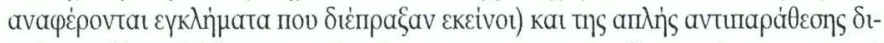

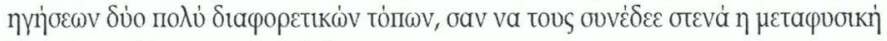

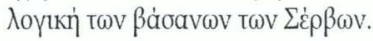

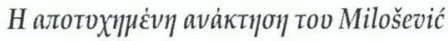

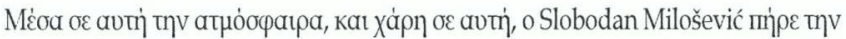

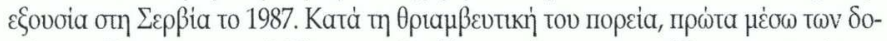

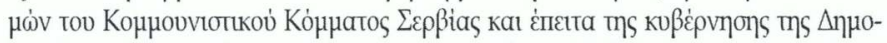

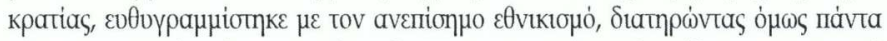

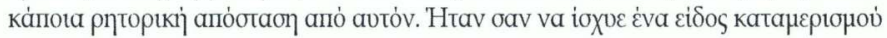

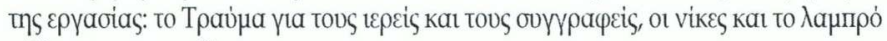

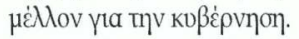

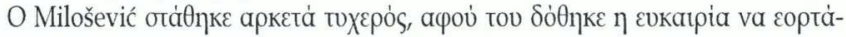

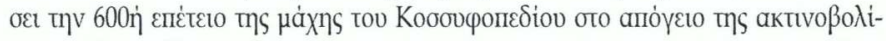

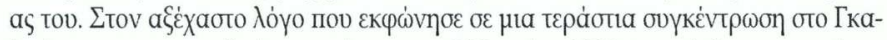

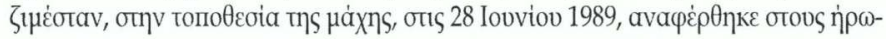

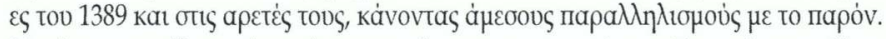

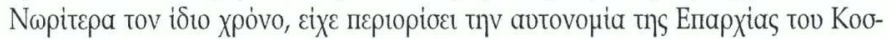

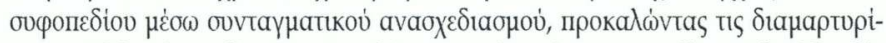

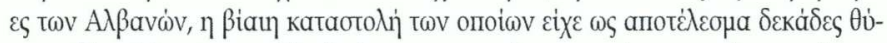

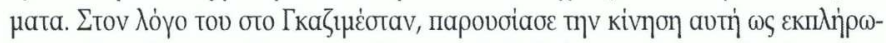

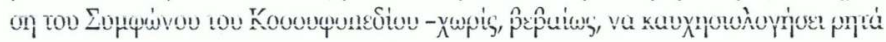




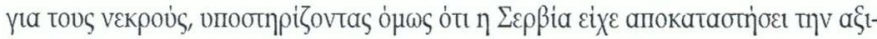

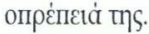

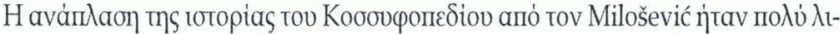

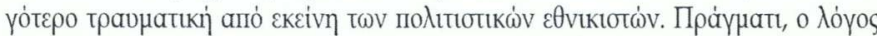

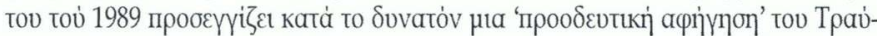

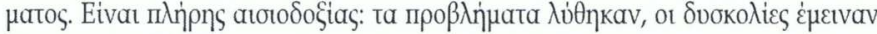

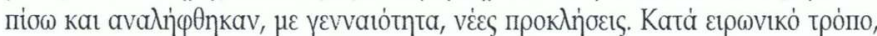

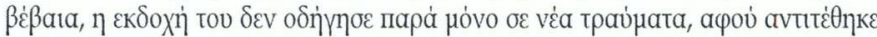

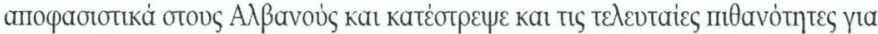

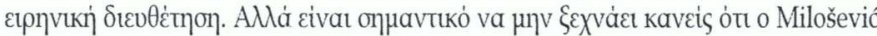

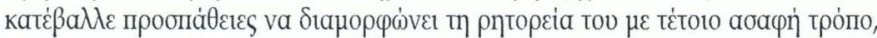
ஸ்

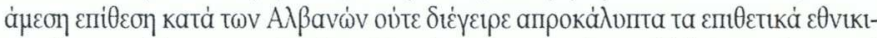

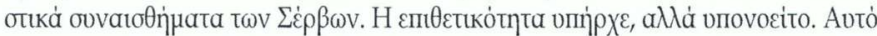

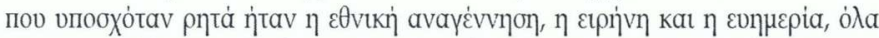

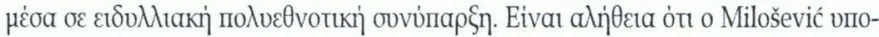

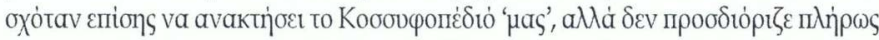

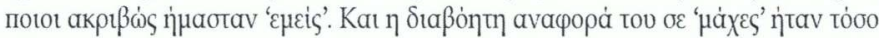

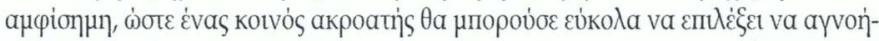

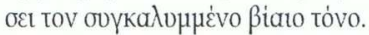

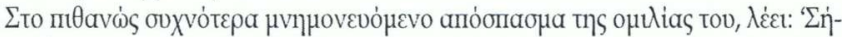
$\mu \varepsilon p a, \varepsilon \dot{\varepsilon} ı$ aเ

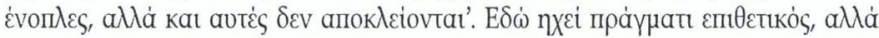

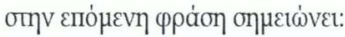

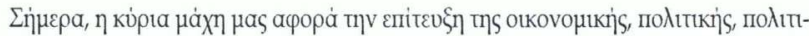

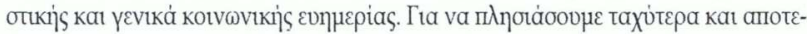

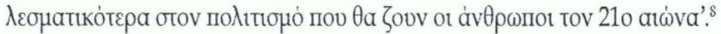

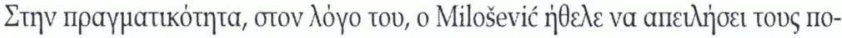

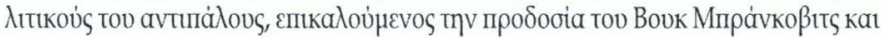

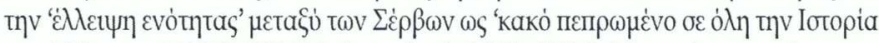

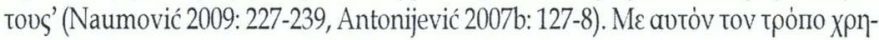

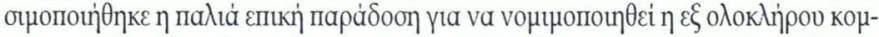

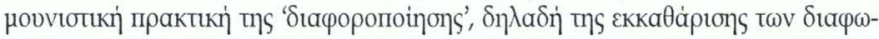

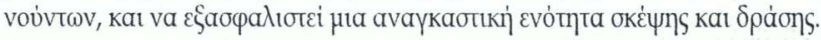




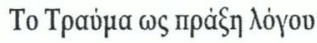

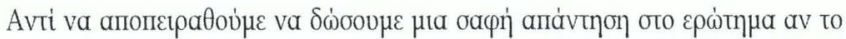

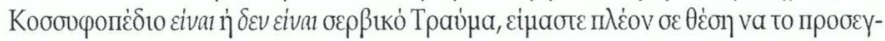

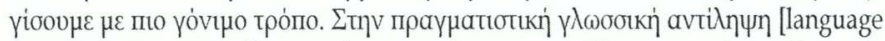

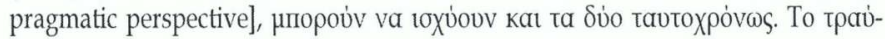

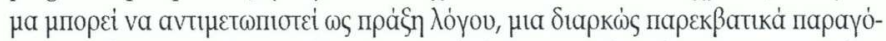

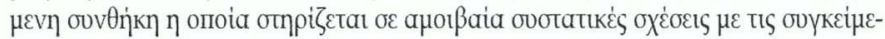

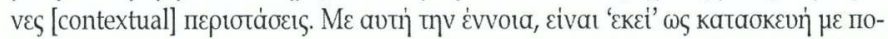

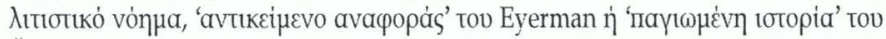

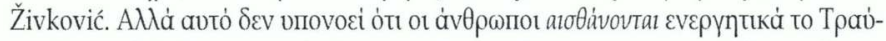

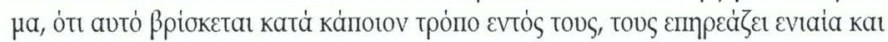

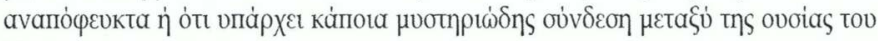

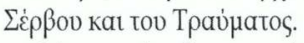

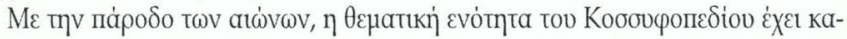

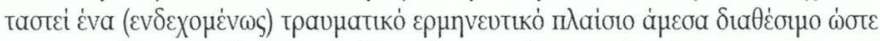

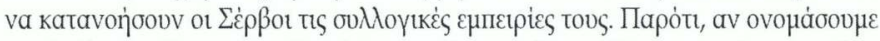

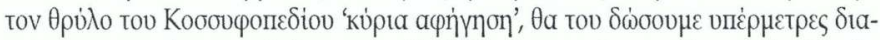

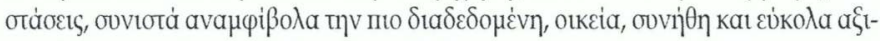

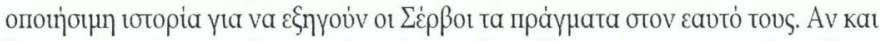

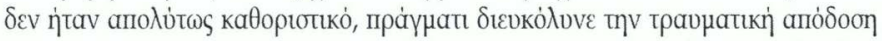

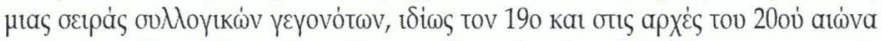

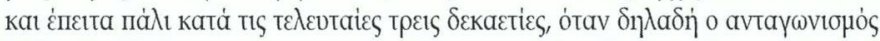

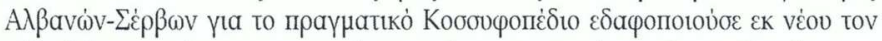

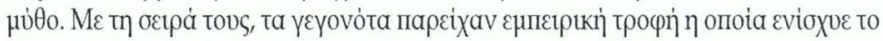

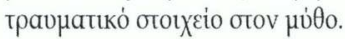

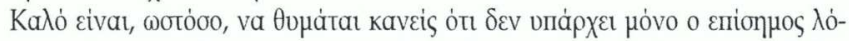

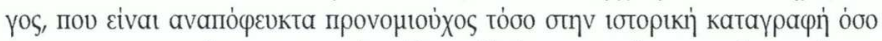

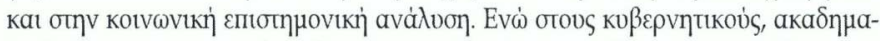

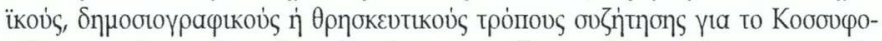

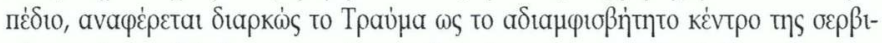

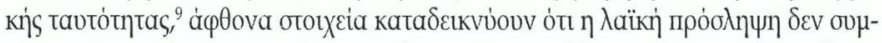

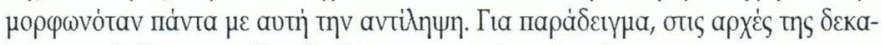

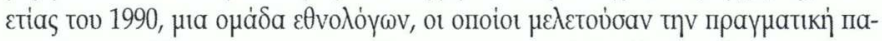

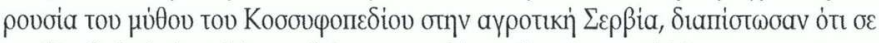

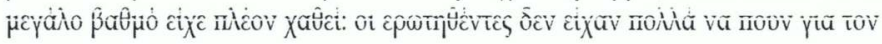




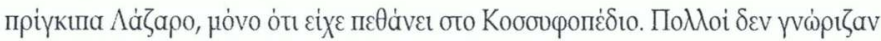

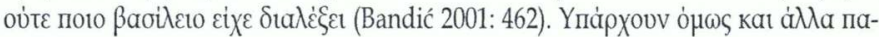
рабвiүната.

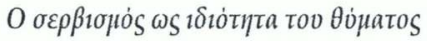

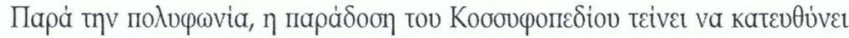

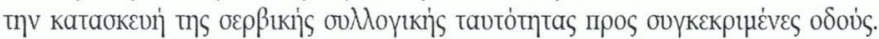

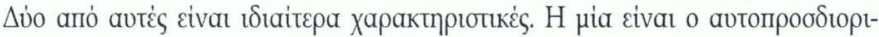

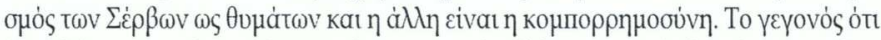
‘ع

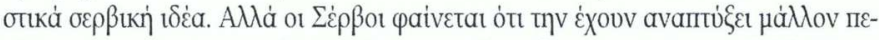

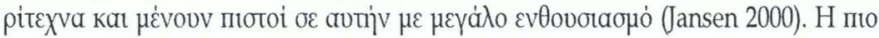

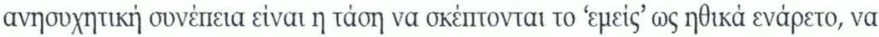

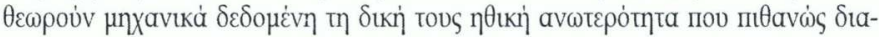

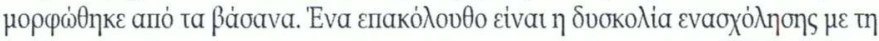

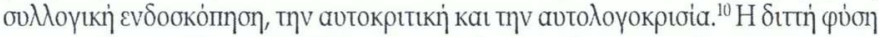

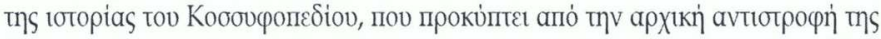

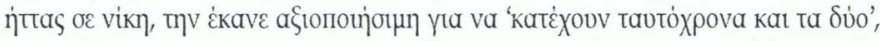

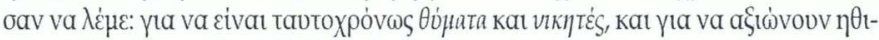

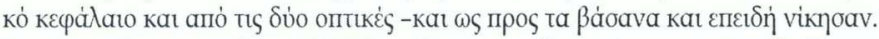

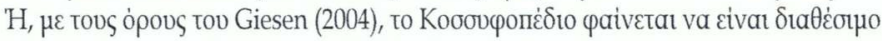

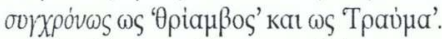

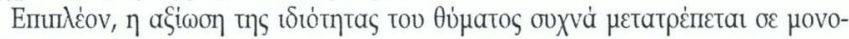

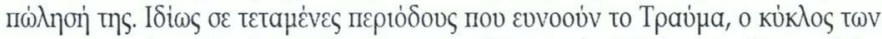

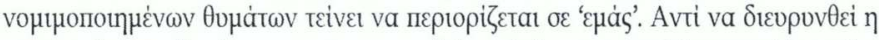

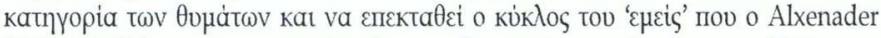

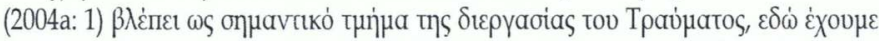

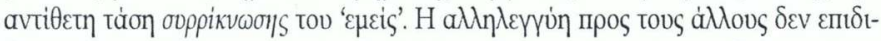

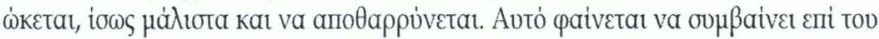

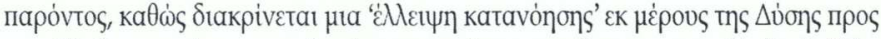

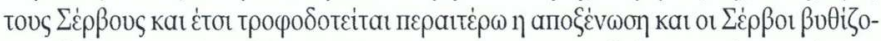

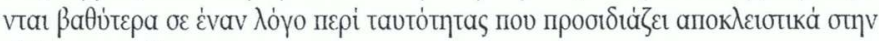

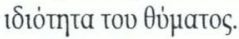

H ठ

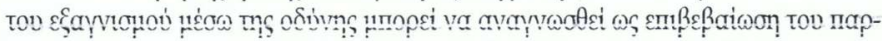

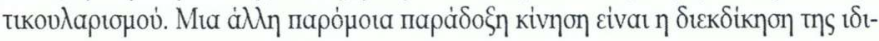




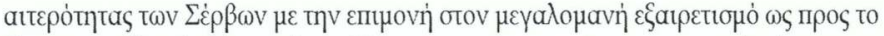

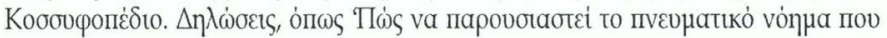

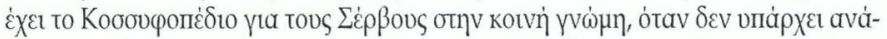

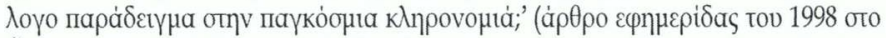

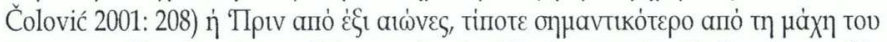

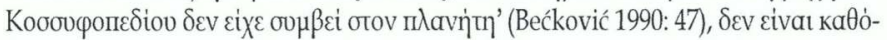

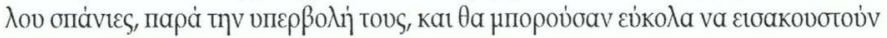
anó тo бepßtкó Kotvó.

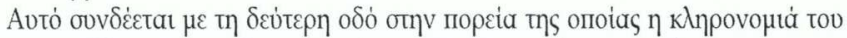

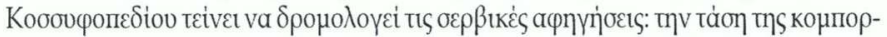

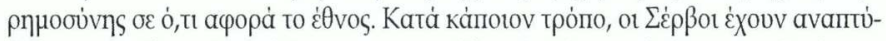

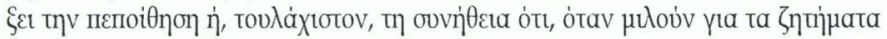

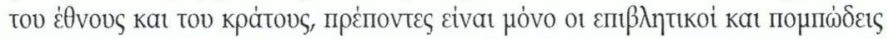

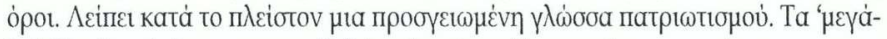

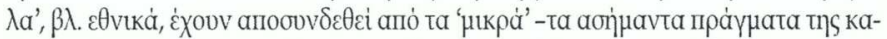

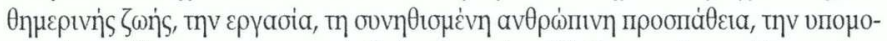

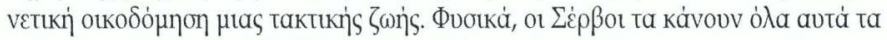

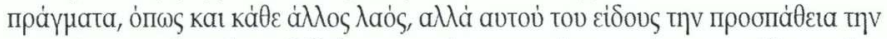

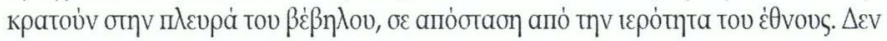

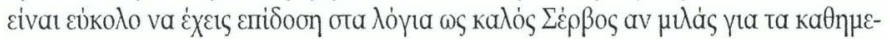

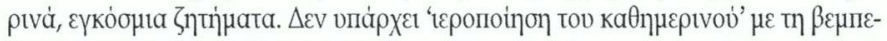

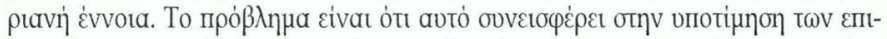

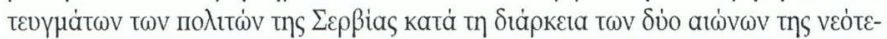

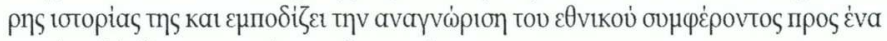

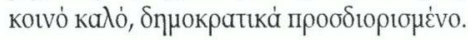

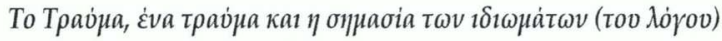

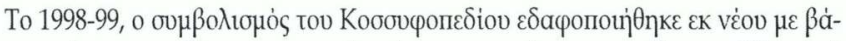

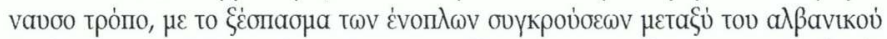

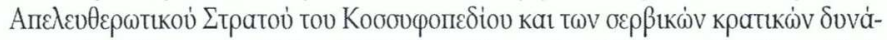

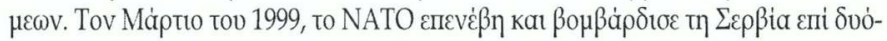

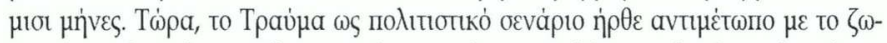

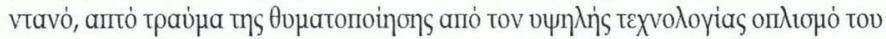

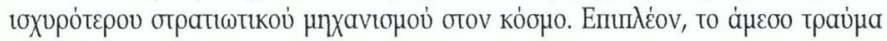

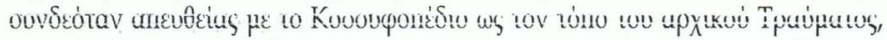

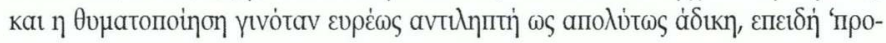




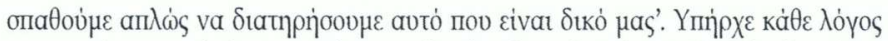

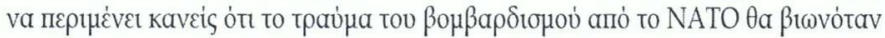

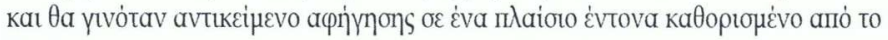
Tрайна.

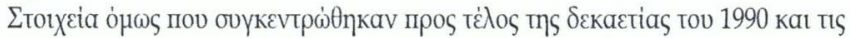

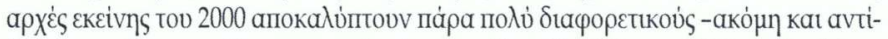

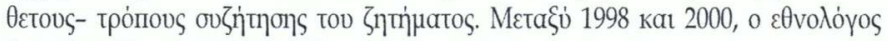

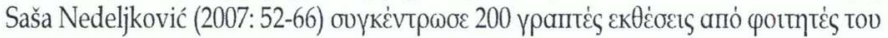

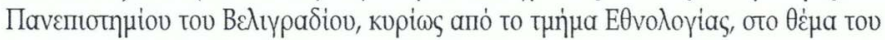

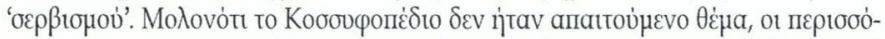

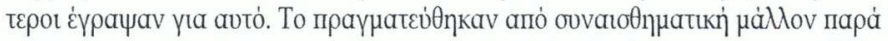

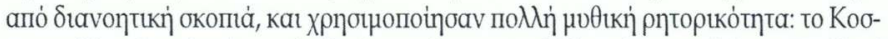

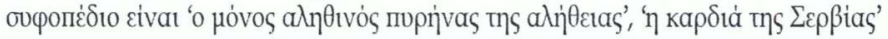

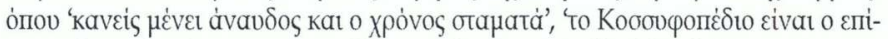

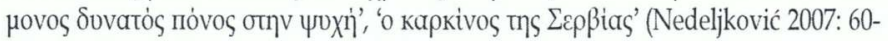

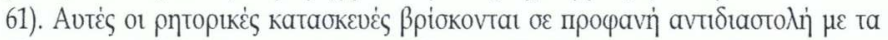

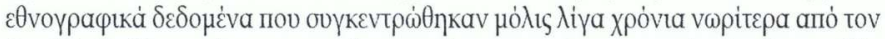

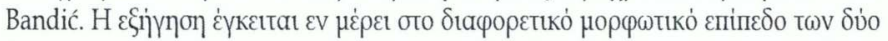

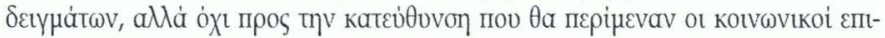

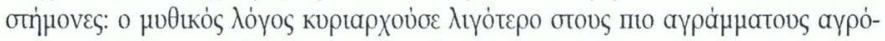

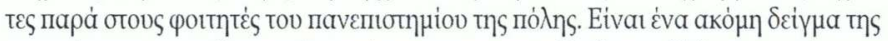

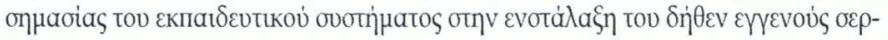

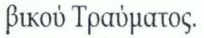

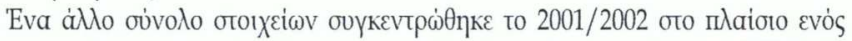

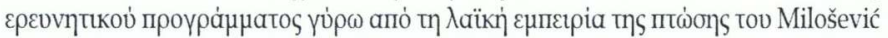

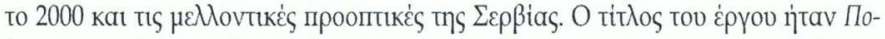

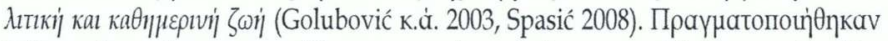

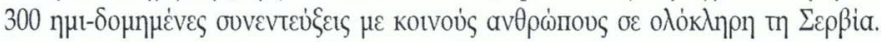

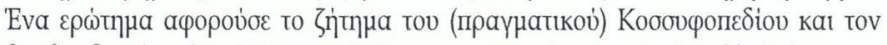

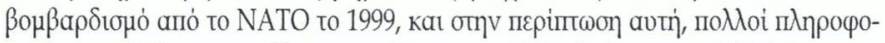

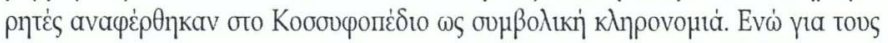

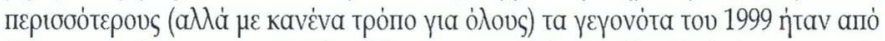

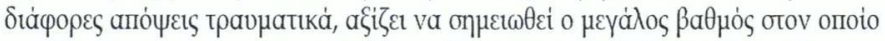

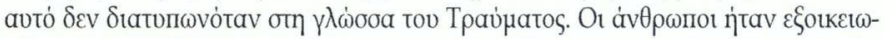

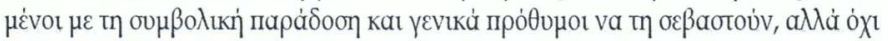

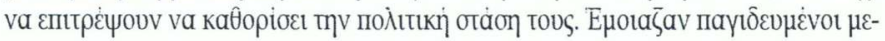




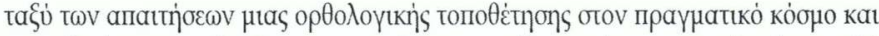

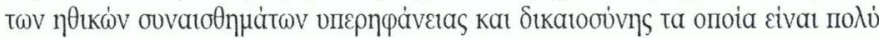

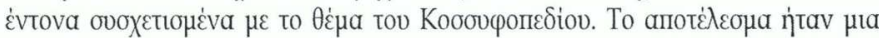

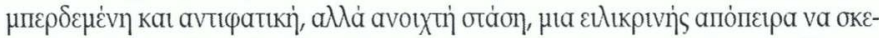

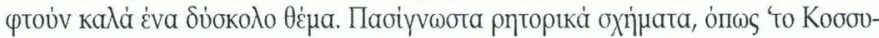

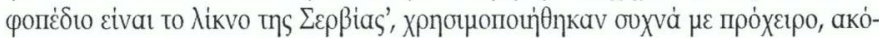

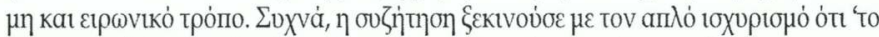

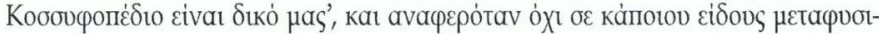

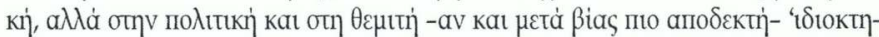

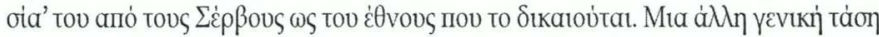

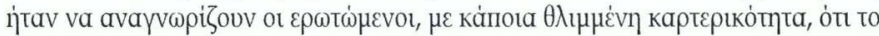

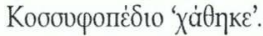

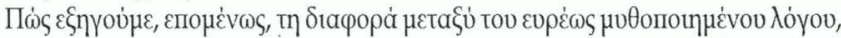

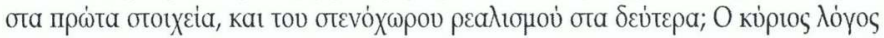

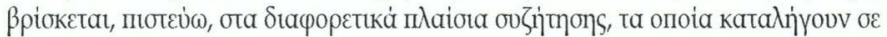

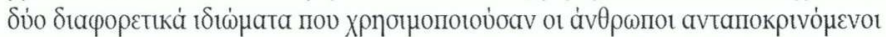

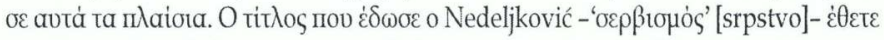

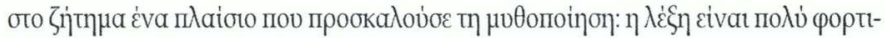

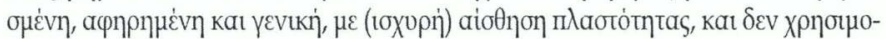

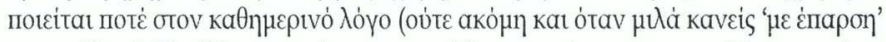

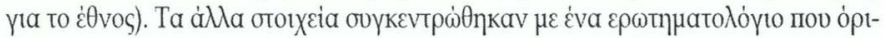

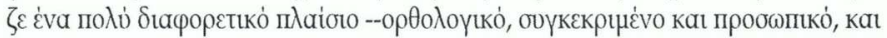

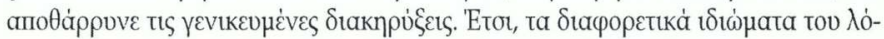

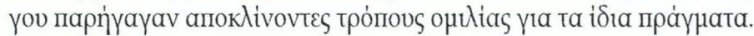

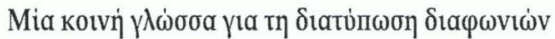

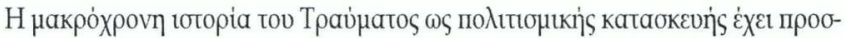

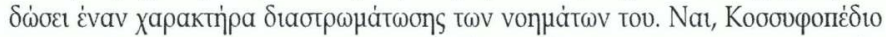

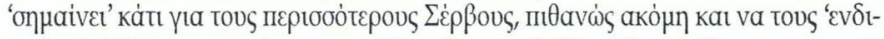

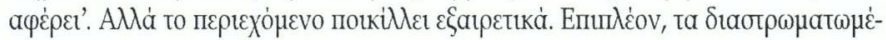

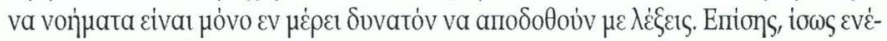

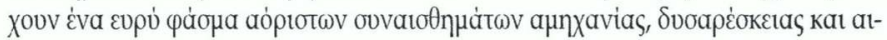

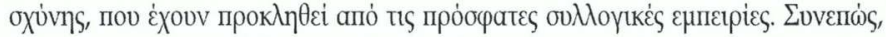

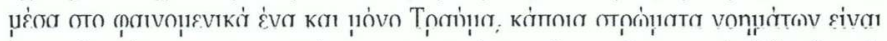

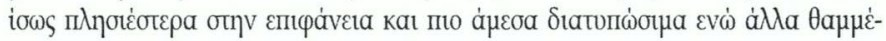




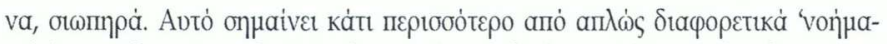

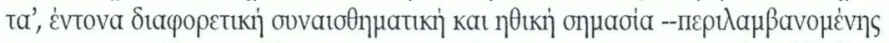

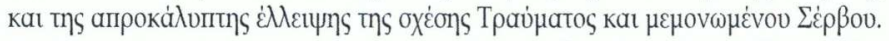

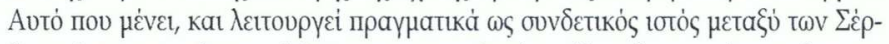

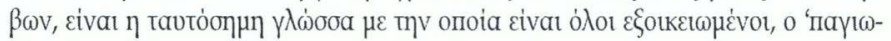

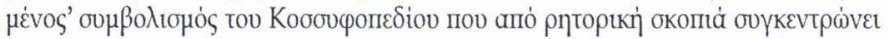

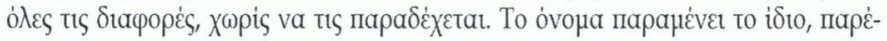

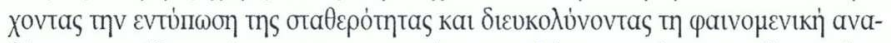

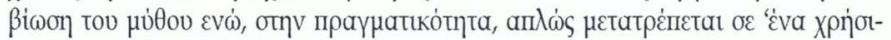

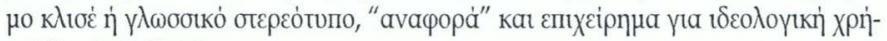
ơ' (Đerić 2005: 30).

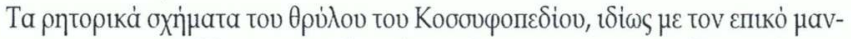

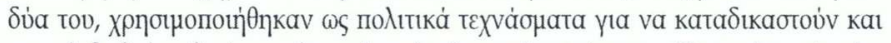

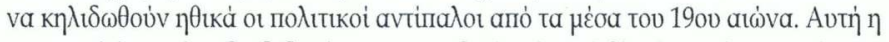

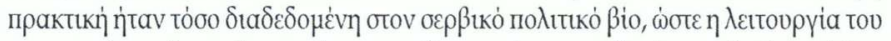

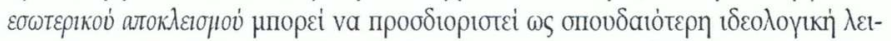

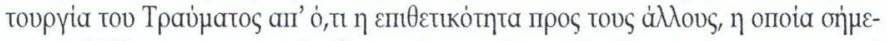

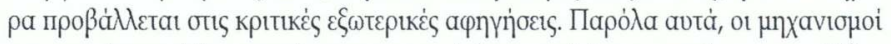

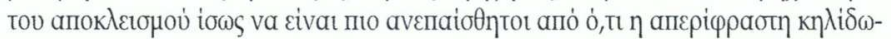

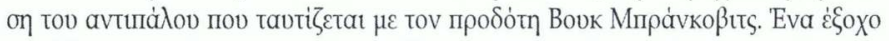

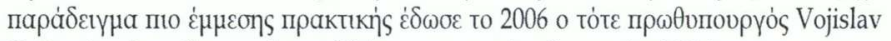

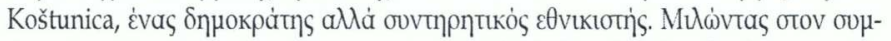

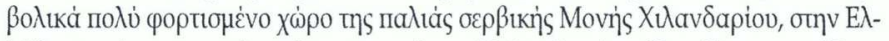

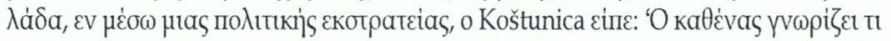

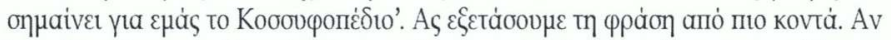

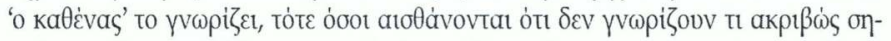

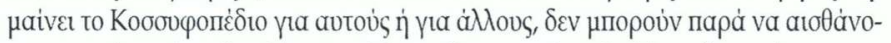

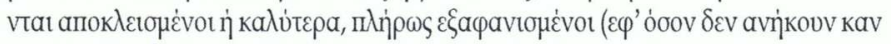

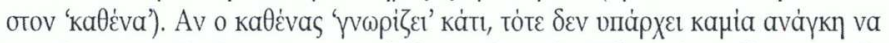

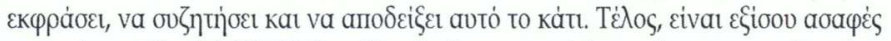

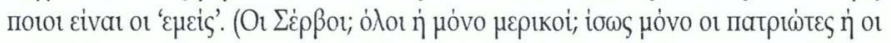

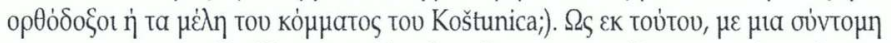

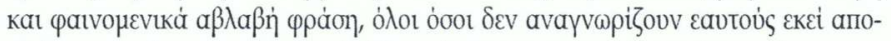

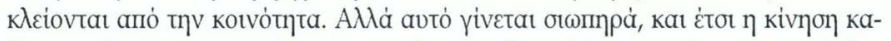

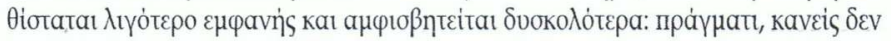

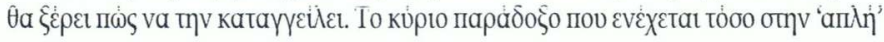




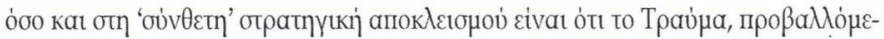

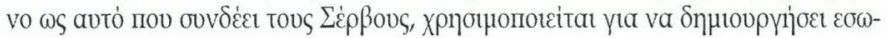

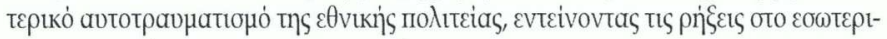
ко́ кат апотре́поvтац тоv катеvvабні́ tous.

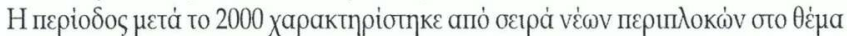

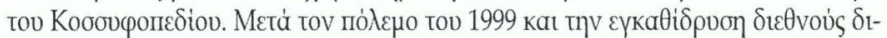

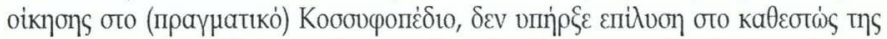

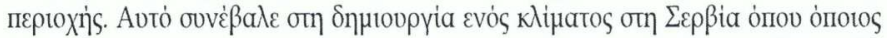

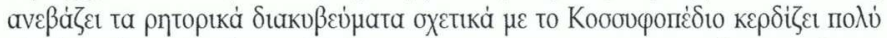

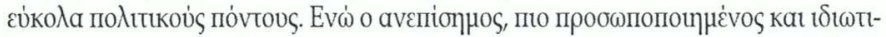

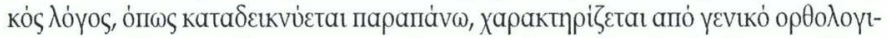

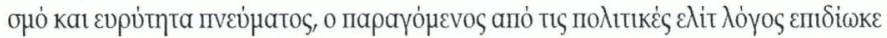

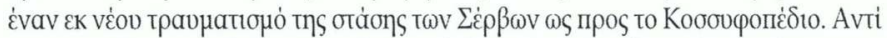

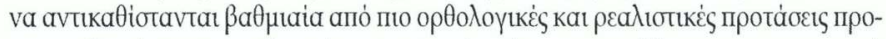

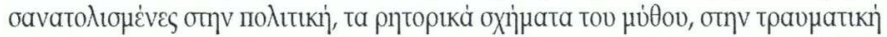

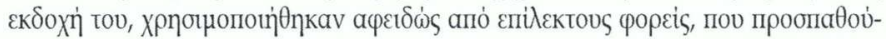

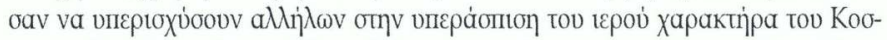

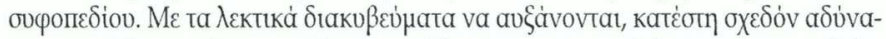

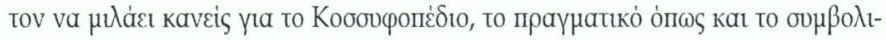

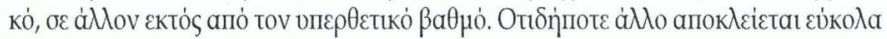

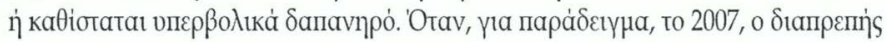

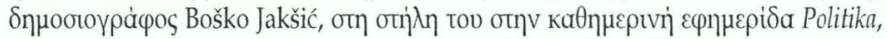

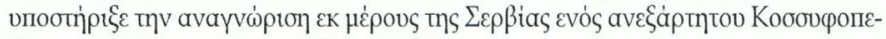

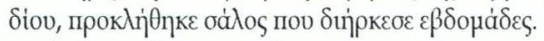

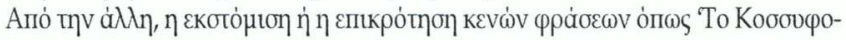

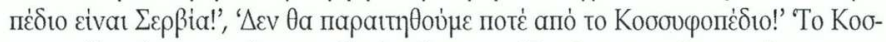

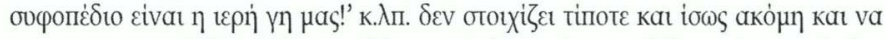

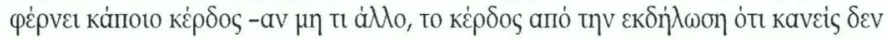

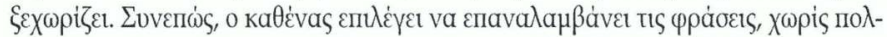

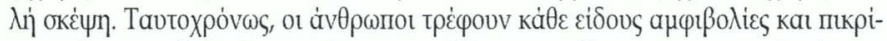

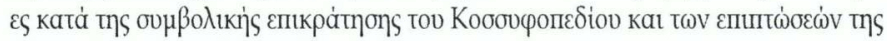

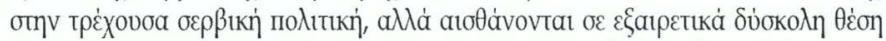

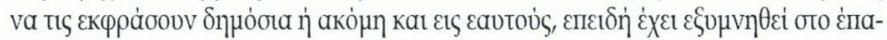

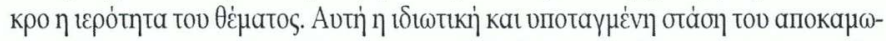

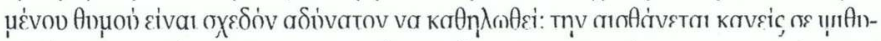

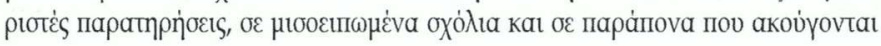




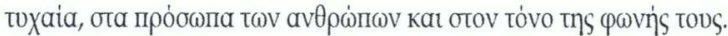

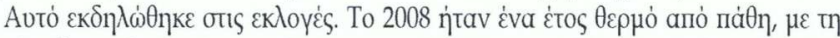

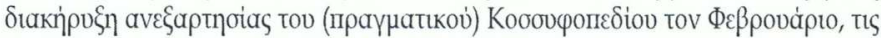

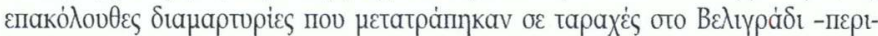

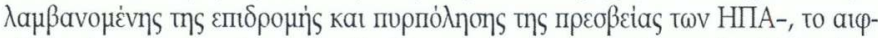

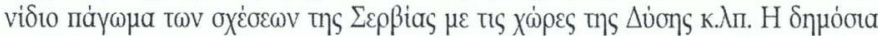

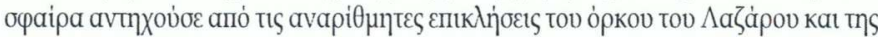

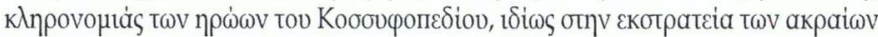

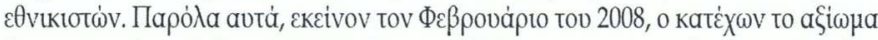

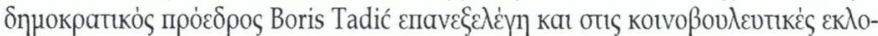

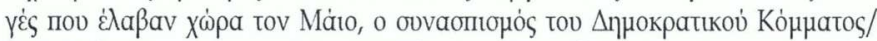

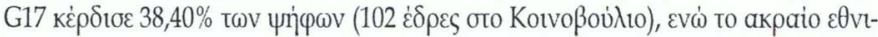

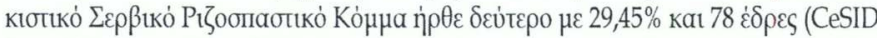

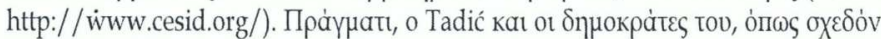

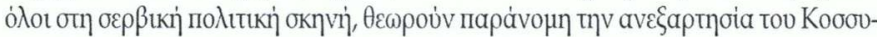

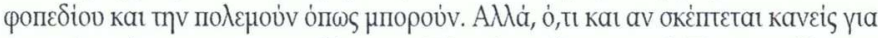

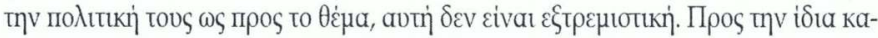

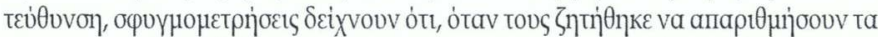

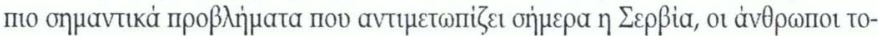

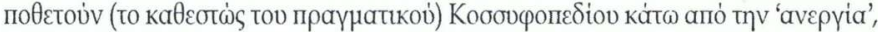

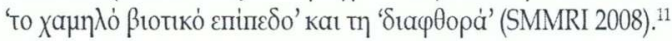

\section{Епілоүоs}

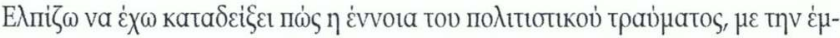

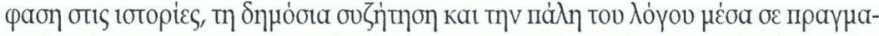

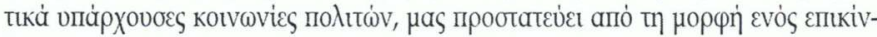

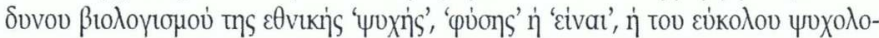

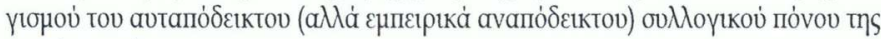

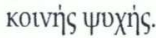

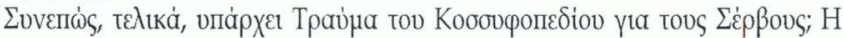

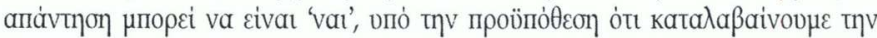

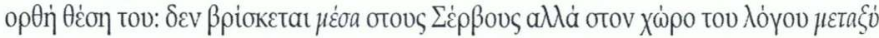

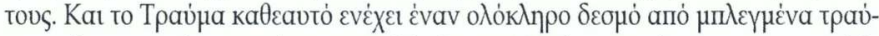

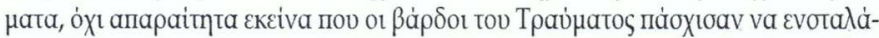

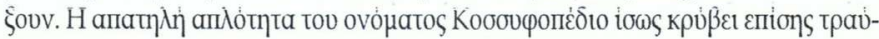




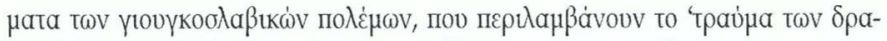

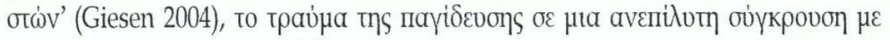

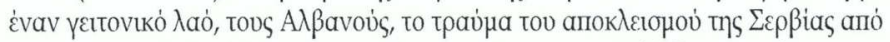

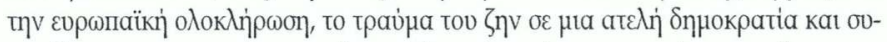

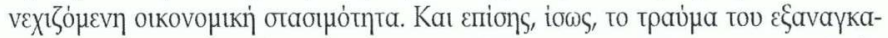

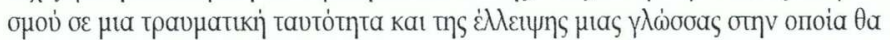

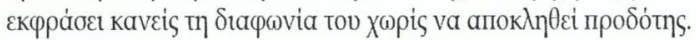

\section{$\Sigma \eta \mu \varepsilon เ \omega \dot{\sigma \varepsilon \varepsilon \varsigma}$}

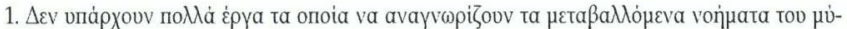

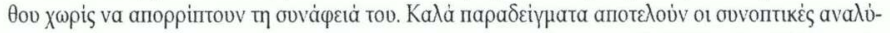

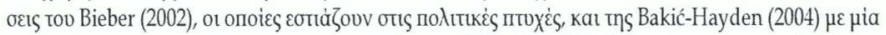

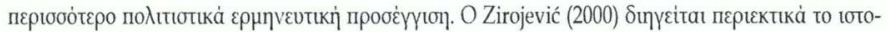

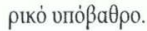

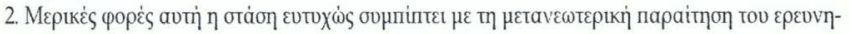

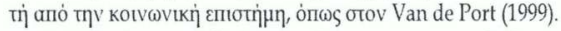

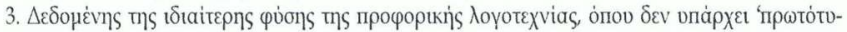

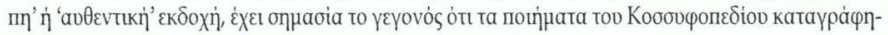

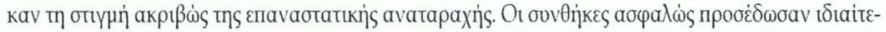

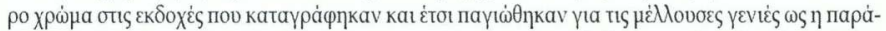

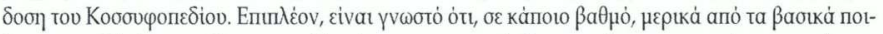

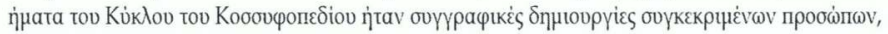

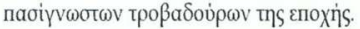

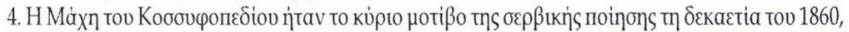

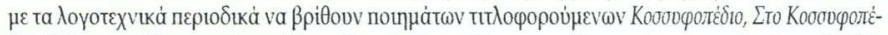

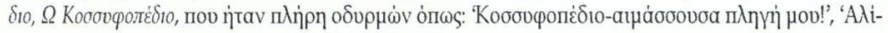

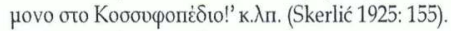

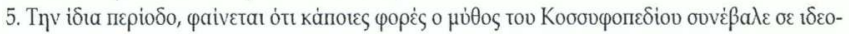

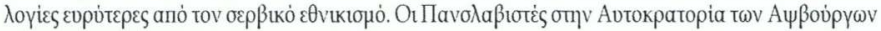

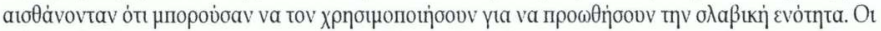

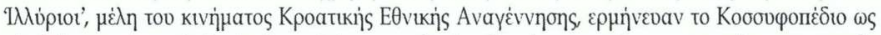

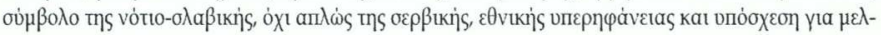

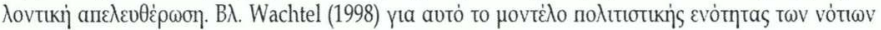

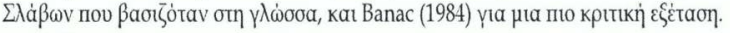

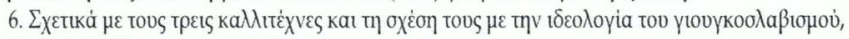
$\beta \lambda$. Wachtel (1998) кaı Banac (1984).

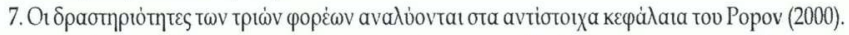

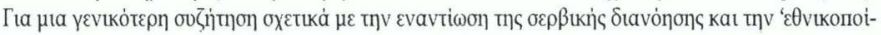

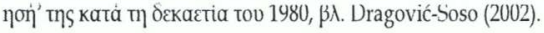


8. ПаратіӨctaı бто: www.uio.no/studier/emner/hf/ilos/BKS4110/Eksamensoppgaver/ BKS $4110 \%$ 20V07.doc.

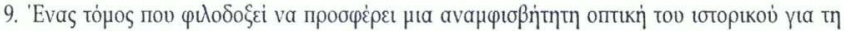

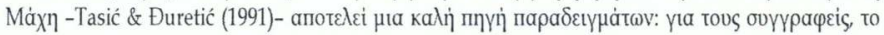

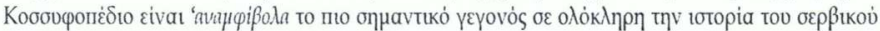

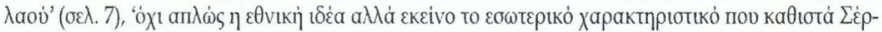

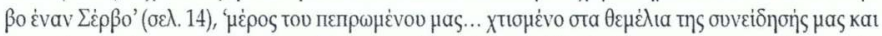

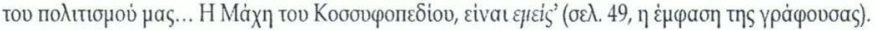

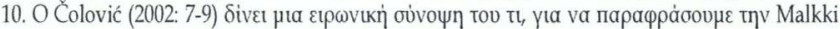

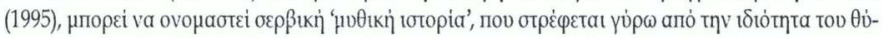

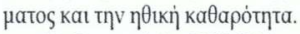

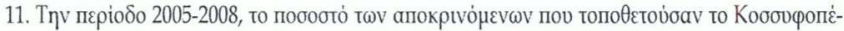

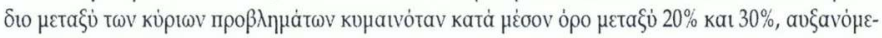

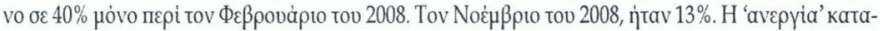
үрафо́таv ба

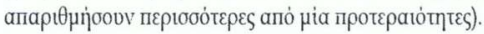

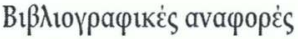

Alexander, J. (2004). 'Toward a Theory of Cultural Trauma', ото J. Alexander et al., Cultural Trauma and Collective Identity, Berkeley: University of California Press.

Antonijević, D. (2007a). Karadorde i Miloš: Izmedu istorije i predanja [Karatorde ka Miloš: $\mu \varepsilon t a-$

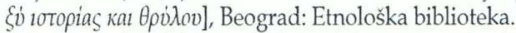

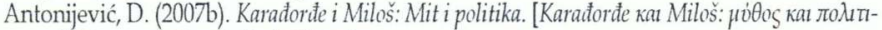
kij], Beograd: Etnološka biblioteka.

Anzulović, B. (1999). Heavenly Serbia: From Myth to Genocide, New York: New York University Press.

Bakić-Hayden, M. (2004). National Memory as Narrative Memory: The Case of Kosovo', бо M. Todorova (єпчн.), Balkan Identities: Nation and Memory, New York: New York University Press.

Banac, I. (1984). The National Question in Yugoslnvia: Origins, History, Politics, Ithaca: Cornell University Press.

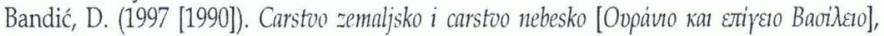
Beograd: XX vek.

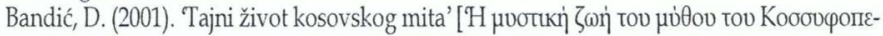

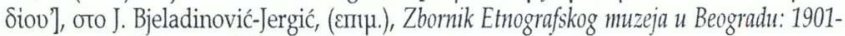
2001. Beograd: Etnografski muzej.

Bećković, M. (1990). Služba [H ustppevia], Beograd: SKZ.

Bieber, F. (2002). Nationalist Mobilization and Stories of Serb Suffering: The Kosovo Myth from 600th Anniversary to the Present', Rethinking History, 6(1): 95-110.

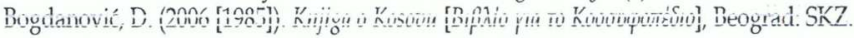


Byford, J. (2008). Denial and Repression of Anti-Semitism: Post-Communist Remembrance of the Serbian Bishop Nikolaj Velimirović, Budapest: CEU Press.

Cvijić, J. (1992 [1931]). 'Dinarski, centralni i panonski tip', ото B. Jovanović, (єпц..)

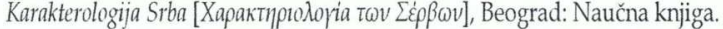

Čolović, I. (2001). Dubina. [BäOos] Beograd: Samizdat B92.

Colović, I. (2002 [1997]). The Politics of Symbol in Serbia: Essays in Political Antliropology, transl. C. Hawkesworth. London: Hurst.

Ćosić, D. (2004). Kosovo. Beograd: Novosti.

Di Lellio, A. (2009). The Battle of Kosovo 1389. An Albanian Epic. London/New York: I.B. Tauris.

DiLellio, A.\&St.Schwandner-Sievers(2006). The Legendary Commander: the Construction of an Albanian Master-Narrative in Post-War Kosovo', Nations and Nationalism 12(3): 513-529.

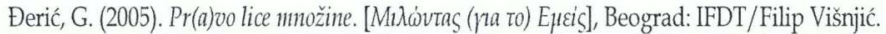

Dragnich, A, \& S. Todorovich (1984). The Saga of Kosovo: Focus on Serbian-Albanian Relations. Boulder, CO: East European Monographs.

Dragović-Soso, J. (2002). Saviours of the Nation?: Serbia's Intellectual Opposition and the Revival of Nationalism. London: Hurst.

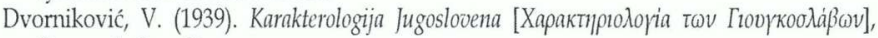
Beograd: Geca Kon.

Duijzings, G. (2000). Religion and the Politics of Identity in Kosovo. London: Hurst.

Emmert, T. A. (1990). Serbian Golgotha: Kosovo 1389. New York: Columbia University Press.

Eyerman, R. (2002). Cultural Trauma. Port Chester, NY: Cambridge University Press.

Giesen, B. (2004). The Trauma of Perpetrators: The Holocaust as the Traumatic Reference of German National Identity', oro J. Alexander et al., Cultural Trauma and Collective Identity. Berkeley: University of California Press.

Golubović, Z, I. Spasić \& Đ. Pavićević, (єnu.) 2003. Politika i suakodneoni život: Srbija 1999-

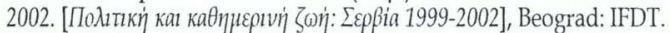

Hobsbawm, E. (1983). Mass-Producing Traditions: Europe, 1870-1914', ото E. Hobsbawm $\&$ T. Ranger, вmц. The Invention of Tradition. Cambridge: Cambridge University Press.

Jansen, S. (2000). Victims, Underdogs and Rebels: Discursive Practices of Resistance in Serbian Protest', Critique of Anthropology 20(4): 393-419.

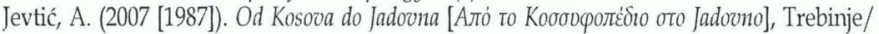
Vrnjci: Manastir Tvrdoš/ Bratstvo sv. Simeona Mirotočivog.

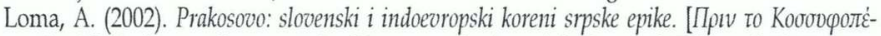

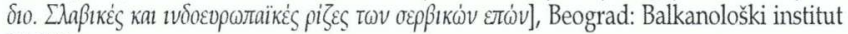
SANU.

Luci, N \& P. Marković (2009). 'Events and Sites of Difference: Marking Self and Other in Kosovo', ото Pål Kolstø, впи.., Media Discourse and the Yugoslav Conflicts. Farnham: Ashgate.

Malcolm, N. (1998). Kos0vo: A Short History. New York: New York University Press. 
Malkki, L. (1995). Purity and Exile: Violence, Memory and National Cosmology among Hutu Refugees in Tanzania. Chicago \& London: University of Chicago Press.

Naumović, S. (2009). Upotreba tradicije u političkom i jarnom životu Srbije na kraju 20. i početkom

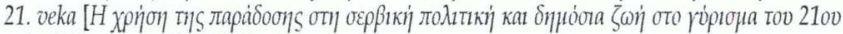
aı

Nedeljković, S. (2007). Čast, kıvi suze [Tipi, aiła kat Sákpva], Beograd: Zlatni zmaj/Odeljenje za etnologiju i antropologiju Filozofskog fakulteta.

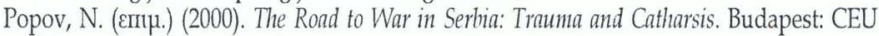
Press.

Popović, M. (1998). Vidoodan i časni krst. [Vidoodan kat o Tipros Stavoós], Beograd: XX vek.

Ramet, S. P. (1995). The Serbian Church and the Serbian Nation', oro S.P. Ramet \& Lj.S. Adamovich, emtu., Beyond Yugoslavia: Politics, Economics, and Culture in a Shattered Comimunity. Boulder: Westview Press.

Roudometof, V. (2001). Nationalism, Globalization, and Orthodoxy. The Social Origins of Ethnic Conflict in the Balkans. Westport, CT: Greenwood Press.

Sells, M A. (2002). The Construction of Islam in Serbian Religious Mythology and Its Consequences', бто M. Schatzmiller, eпru., Islam and Bosnia: Conflict Resolution and Foreign Policy in Multi-Ethnic States. Montreal \& Kingston: McGill-Queen's University Press.

Skerlić, J. (1925). Omladina i njena književnost (1848-1871). Izučavanja o nacionalnom $i$

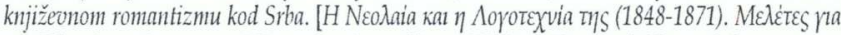

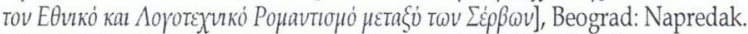

SMMRI (2008). 'Attitudes concerning Kosovo', Monthly Onnibus Survey, Strategic Marketing Research. Belgrade.

Spasić, I. (2008). 'Serbia 2000-2008: A Changing Political Culture?' Balkanologie 11(1-2), http:// balkanologie.revues.org/index1282.html

Suber, D. (2006). Myth, collective trauma and war in Serbia: a cultural-hermeneutical appraisal', Anthropology Matters Journal 8(1): 1-9.

Tasić, N. \& V. Đuretić, (єпц.), (1991). Kosouska bitka 1389. i njene posledice [H Máxy too Koo-

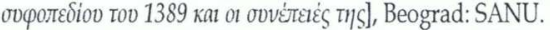

Van de Port, M. (1999). "It Takes a Serb to Know a Serb": Uncovering the Roots of Obstinate Otherness in Serbia', Critique of Anthropology 19(1): 7-30.

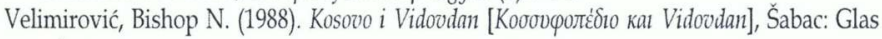
crkve.

Vetlesen, A. J. (2005). Evil and Human Agency: Understanding Collective Evildoing. Cambridge: Cambridge U. Press.

Vickers, M. (1998). Between Serb and Albanian: A History of Kosovo. London: Hurst.

Volkan, V. D. (1996). 'Bosnia-Herzegovina: Ancient Fuel of a Modern Inferno', Mind and Human Interaction 7: 110-127.

Volkan, V.D. (2002). Bosnia-Herzegovina: Chosen Trauma and Its Transgenerational Transmission', ото M. Schatzmiller, eпu... Islam and Bosnia. Montreal \& Kingston: McGill-Queen's University Press. 
Vucinich, W.S., \& T.A. Emmert (enц.) (1991). Kosovo: Legacy of a Medieval Battle. Minneapolis: University of Minnesota Press.

Wachtel, A. B. (1998). Making a Nation, Breaking a Nation: Literature and Cultural Politics in Yugoslavia. Stanford: Stanford University Press.

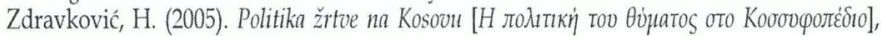
Beograd: Etnološka biblioteka.

Zirojević, O. (2000). Kosovo in the Collective Memory', oro N. Popov, єпu., The Rond to War in Serbin: Trauma and Catharsis. Budapest: CEU Press.

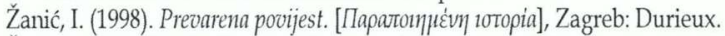

Živković, M. (2001). 'Serbian Stories of Identity and Destiny in the 1980s and 1990s', Unpublished Ph.D. dissertation, Department of Anthropology, University of Chicago. 